\title{
Integrated Segmentation Approach with Machine Learning Classifier in Detecting and Mapping Post Selective Logging Impacts Using UAV Imagery
}

\author{
Aisyah Marliza Muhmad Kamarulzaman ${ }^{1}$, Wan Shafrina Wan Mohd Jaafar ${ }^{1, *(1)}$, \\ Khairul Nizam Abdul Maulud ${ }^{1,2} \mathbb{\infty}$, Siti Nor Maizah Saad ${ }^{1,3}$, Hamdan Omar ${ }^{4}{ }^{\mathbb{D}}$ and Midhun Mohan ${ }^{5}$ \\ 1 Earth Observation Centre, Institute of Climate Change, Universiti Kebangsaan Malaysia, \\ Bangi 43600, Selangor, Malaysia; p103420@siswa.ukm.edu.my (A.M.M.K.); \\ knam@ukm.edu.my (K.N.A.M.); normaizah@uitm.edu.my (S.N.M.S.) \\ 2 Department of Civil Engineering, Faculty of Engineering and Built Environment, \\ Universiti Kebangsaan Malaysia, Bangi 43600, Selangor, Malaysia \\ 3 Department of Surveying Science and Geomatics, Faculty of Architecture, Planning and Surveying, \\ Universiti Teknologi Mara, Arau 02600, Perlis, Malaysia \\ 4 Forest Research Institute Malaysia, Kepong 52109, Selangor, Malaysia; hamdanomar@frim.gov.my \\ 5 Department of Geography, University of California-Berkeley, Berkeley, CA 94709, USA; \\ mid_mohan@berkeley.edu \\ * Correspondence: wanshafrina@ukm.edu.my; Tel.: +60-3-89216941
}

check for

updates

Citation: Kamarulzaman, A.M.M.; Wan Mohd Jaafar, W.S.; Abdul Maulud, K.N.; Saad, S.N.M.; Omar, H.; Mohan, M. Integrated Segmentation Approach with Machine Learning Classifier in Detecting and Mapping Post Selective Logging Impacts Using UAV Imagery. Forests 2022, 13, 48. https://doi.org/ 10.3390/f13010048

Academic Editor: Steven L. Petersen

Received: 15 October 2021

Accepted: 8 December 2021

Published: 2 January 2022

Publisher's Note: MDPI stays neutral with regard to jurisdictional claims in published maps and institutional affiliations.

Copyright: (c) 2022 by the authors. Licensee MDPI, Basel, Switzerland. This article is an open access article distributed under the terms and conditions of the Creative Commons Attribution (CC BY) license (https:/ / creativecommons.org/licenses/by/ $4.0 /)$.
Abstract: Selective logging can cause significant impacts on the residual stands, affecting biodiversity and leading to environmental changes. Proper monitoring and mapping of the impacts from logging activities, such as the stumps, felled logs, roads, skid trails, and forest canopy gaps, are crucial for sustainable forest management operations. The purpose of this study is to assess the indicators of selective logging impacts by detecting the individual stumps as the main indicators, evaluating the performance of classification methods to assess the impacts and identifying forest gaps from selective logging activities. The combination of forest inventory field plots and unmanned aerial vehicle (UAV) RGB and overlapped imaged were used in this study to assess these impacts. The study area is located in Ulu Jelai Forest Reserve in the central part of Peninsular Malaysia, covering an experimental study area of $48 \mathrm{ha}$. The study involved the integration of template matching (TM), object-based image analysis (OBIA), and machine learning classification-support vector machine (SVM) and artificial neural network (ANN). Forest features and tree stumps were classified, and the canopy height model was used for detecting forest canopy gaps in the post selective logging region. Stump detection using the integration of TM and OBIA produced an accuracy of $75.8 \%$ when compared with the ground data. Forest classification using SVM and ANN methods were adopted to extract other impacts from logging activities such as skid trails, felled logs, roads and forest canopy gaps. These methods provided an overall accuracy of $85 \%$ and kappa coefficient value of 0.74 when compared with conventional classifier. The logging operation also caused an $18.6 \%$ loss of canopy cover. The result derived from this study highlights the potential use of UAVs for efficient post logging impact analysis and can be used to complement conventional forest inventory practices.

Keywords: selective logging impacts; UAV; object-based image analysis; machine learning; forest classification

\section{Introduction}

The rainforests of Malaysia are one of the most species-rich and biologically diverse tropical ecosystems with a considerable number of endemic species. Malaysia has at least 10,000 flowering plant species, of which 2830 are tree species from Peninsular Malaysia. Malaysia's cumulative natural forest area was about 18.27 million ha or $55.60 \%$ of the country's total land area of 32.86 million ha [1]. However, there are concerns about the 
degradation and depletion of forest resources and many species are known to have a risk of extinction [2]. An extensive area of tropical forests has been specifically logged, either legal or illegally [3]. The degradation produced by selective logging will have an impact on the region and the long-term viability of forest management [4]. Malaysian forest authority requires an improvement in forest inventories which have been dependent on traditional field assessment. Time limitations and labour costs are also major challenges [5]. Preservation of forest management requires constant information of forest structure and inventories, which has historically been collected by ground-based surveys but is now increasingly depending on remote sensing technologies as well. Field assessments coupled with remote sensing imagery is appropriate in monitoring logging operations so that forest activities can be carried out in accordance with sustainable forest management criteria. Logging operations life cycle encompasses harvesting or felling trees, movement of trees to the production facility and wood production. Each of these cycles involves forest harvesting practices such as the construction of forest roads, skid trails and log landings for the felled logs [6]. Long-term forest production forecasts and a better knowledge of tropical forest ecosystems under harvesting regimes require precise monitoring.

Remote sensing methods are considered an efficient and cost-effective means of this study, not only because of the improved spatial resolutions of the databases but also they allow the detection of selective logging impacts components [7,8]. High-resolution images produced from Unmanned Aerial Vehicles (UAVs) are one of the useful remote sensing data products for analysing the selective logging impacts offers benefits over traditional survey techniques [9]. The stereo images captured by the optical sensor aboard the UAV can be photogrammetrically processed using $3 \mathrm{D}$ reconstruction software to create a digital terrain model and a digital surface model [10]. Moreover, due to the small-scale size of the region, dispersed dispersion, and limited access to harvest locations, UAVs may be appropriate for site evaluation. UAV imagery is useful for identifying the impacts on post-selective logging such as stumps, roads, skid rails, felled logs and forest gaps [11,12]. One of the most important and strong indicators in selective logging area is a tree stump. Tree stumps in the tropical region are quite homogeneous, and they have a lighter colour layer on the surface than the neighbouring regions that are visible $(10-50 \mathrm{~cm})$ above ground level that will make them difficult to detect in the long-range [13]. Object-based image analysis (OBIA) and object detection-based methods such as template matching (TM) can be used to detect stumps from high-resolution imagery [14]. The key characteristic of most TM algorithms is object boundaries [15]. However, the boundary can become skewed or obscured in certain cases, resulting to an error in identifying the tree stump's shape [16]. In order to minimise the TM constraint and limitation, OBIA technique can be used, with the boundary derived using a segmentation approach. The size of the tree stumps, as well as the segmentation and detection parameters, can result in accurate detection. A combination of TM and OBIA is utilised in this study to increase the accuracy of template matching and improve the technique of tree stump detection on UAV images [14]. The stump amount and results from the integration of TM and OBIA methods will then be identified over the area and also will be set as training datasets for the classification technique together with the other selective logging impacts that are more obvious elements such as roads, skid trails, felled logs and forest. Roads and skid trails can be directly retrieved from the training datasets and can be produced from the classification automatically. Numerous methods are available for image classification that involves traditional approaches such as maximum likelihood, minimum distance, Mahalanobis distance and advanced techniques such as artificial neural network (ANN) and support vector machine (SVM) [17,18]. ANN and SVM are among the most common techniques in machine learning classification [19]. Besides that, forest gaps also play an important role that indicating the various ecological processes and estimates of forest loss in a logging region. In this study, forest gaps were derived using automated approach from UAV's overlapped images by integrating the canopy height model (CHM). 
To generate such information, the automated approach is created to develop appropriate management strategies and to monitor their success. Size and spatial distribution are the most commonly mapped gap parameters for which various remote sensing data and techniques have been used. Recent technical advances in the field of digital photogrammetry demonstrate the great potential of automatic image matching for deriving digital surface models (DSMs) that can be used for the accurate characterization of the forest canopy structure. Extraction of normalized DSMs and digital terrain model (DTM) producing $\mathrm{CHM}$ is useful for estimating the timber volume and is well suited for gap detection [20].

This paper aims to assess the selective logging impacts through the indicators and to monitor forest disturbance on post-selective logging impact areas with advanced remote sensing and GIS (Geographic Information Science) technologies. The study objectives were to: (i) Detect individual stumps and map the presence of the stumps in UAV imagery; (ii) evaluate the applicability of machine learning and conventional classifier for deriving selective logging impacts information from unmanned aerial imagery (also to assess their performance against each other); and (iii) identify the forest gaps area produced by the selective logging activities. Moreover, information from this quantitative study will provide a valuable reference for forest assessment such as forest department by using the advanced technology, thus identifying conservation efforts for sustainability of forest logging practices.

\section{Materials and Methods}

\subsection{Study Area}

The study was conducted at Ulu Jelai Forest Reserve in Lipis, Pahang, Malaysia at a latitude of $101.888^{\circ}$ and a longitude of $4.553^{\circ}$ (Figure 1). The research area is represented by the Forest Reserve area, which generally consists of highly dense vegetation area. It can be found at the forest's height ranges from 300 to $356.54 \mathrm{~m}$ above sea level, with the amount of rainfall averaging from 1500 to $2000 \mathrm{~mL}$. The research area is approximately 48 ha covering three compartments in logging license number 124, 159 and 160 (Figure 1). This area is under the authority of the Pahang Forestry Department and has been selectively logged as part of a Sustainable Forest Management program (SFM). Within each compartment, every tree stump was measured, as well as associated data.

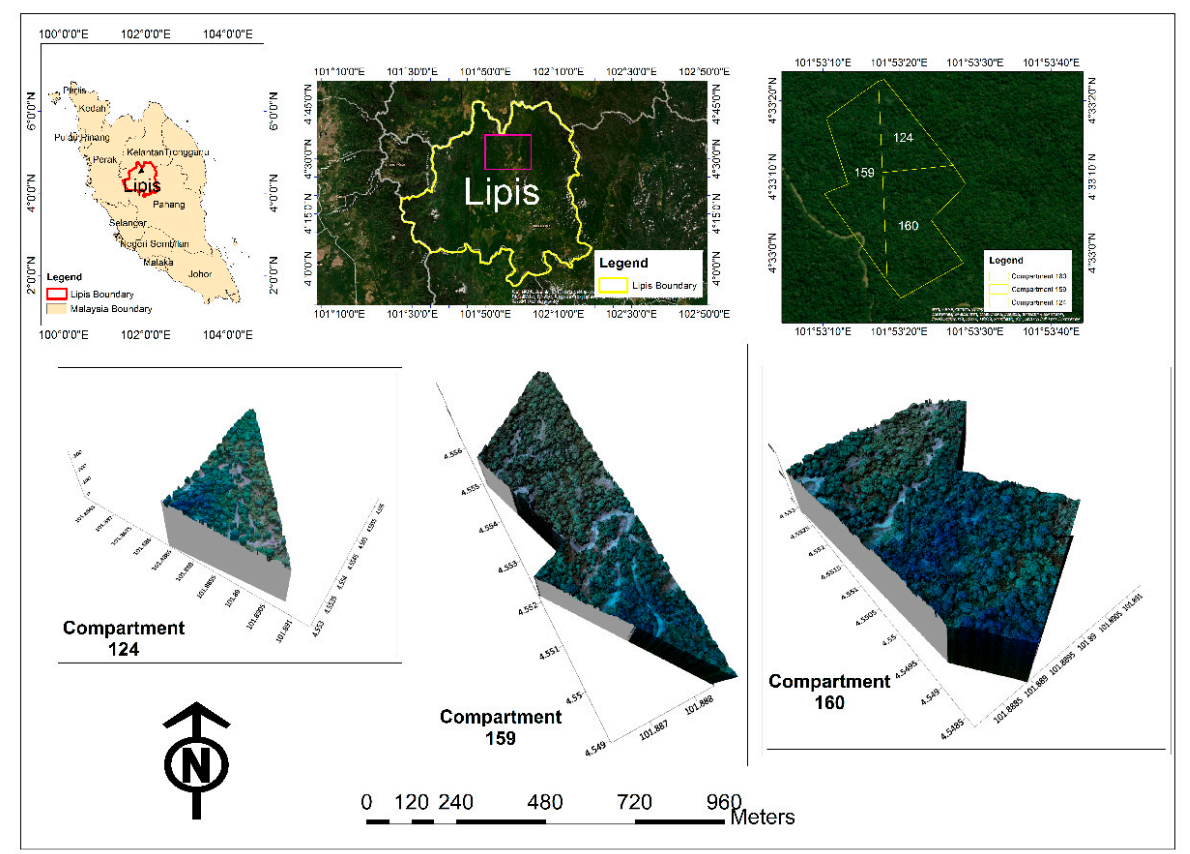

Figure 1. Map of study areas in Ulu Jelai Forest Reserve, Lipis, Pahang, Malaysia. The bottom panel shows the three compartments of logging license 124, 159 and 160. 


\subsection{Methodological Framework}

The detailed workflow for pre-processing and field data, extraction of the stump by using object-based detection, training data, the performance of the classifications of each of the selective logging impacts together with the forest canopy gaps and loss is presented in Figure 2. The impacts occurrence locations were identified by using various data produced from UAV imagery.

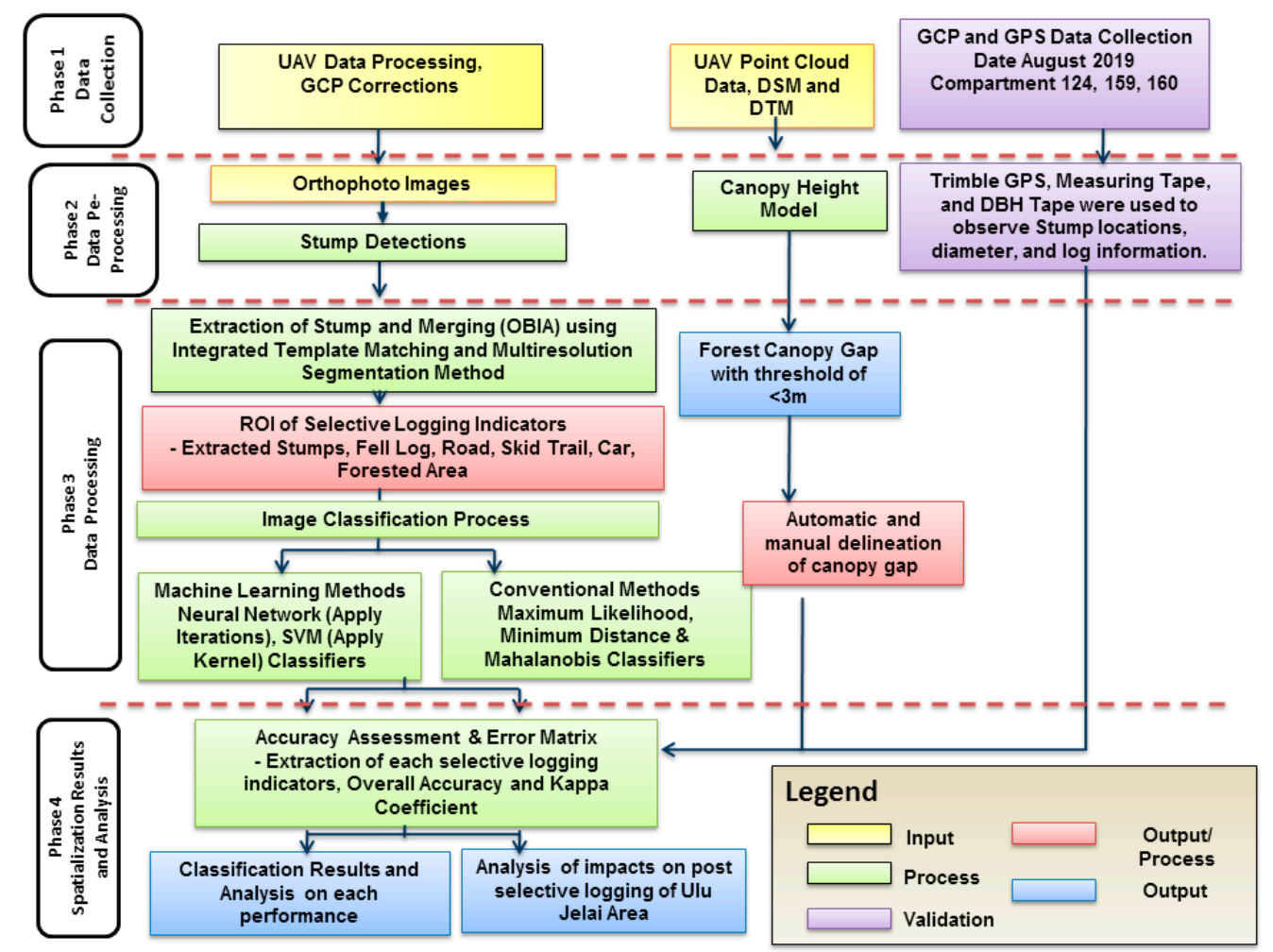

Figure 2. The overall methodological framework on detecting impacts of selective logging.

\subsection{Field Data}

The data utilised in this study is separated into two categories: ground-based data and data from UAV. From 19 August through 23 August 2019, a Trimble GPS Geo7X handheld equipped with a real-time kinematic (RTK) and ready built-in global navigation satellite system (GNSS) was used to take the measurement and determine GCPs by placing it on the centre of the stump. This equipment utilised a live global system for mobile communication (GSM) network with a precision of $50 \mathrm{~cm}$ after post-processing. The GPS Geo7X was used to take the tree stump measurement.

Field data collection included quantifying stump heights and diameters as well as parameters linked to felled logs, such as the size of the log and its branches, incidental damage caused by the fallen log, and logging structures, all of which were recorded in the field specification sheet. The stump and crown of each felled tree were located and validated by calculating the angle of the tree fall, species, and appropriate distance from the stump, as most of the logs had been removed before data acquisition procedures. The stump's height is measured to the tree's end cut (Figure 3a). The tape diameter was used to measure the diameter breast height $(\mathrm{DBH})$. The diameter was measured directly on both $\log$ and stump where the log and stump were still standing (Figure $3 a, d)$ ). The length of the $\log$ (measured in the field) and the cross-sectional areas at the two ends of the log from north to south and east to west were measured. In determining the damage sizes during logging activities, the lengths and widths of logging roads (Figure $3 b$ ) and skid trails (Figure $3 \mathrm{c}$ ) were measured. During the sampling, there were 21 points detected on the ground (Figure 3). 


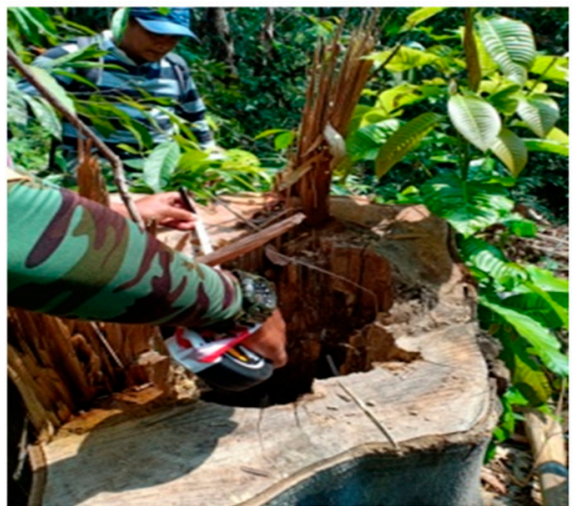

(a)

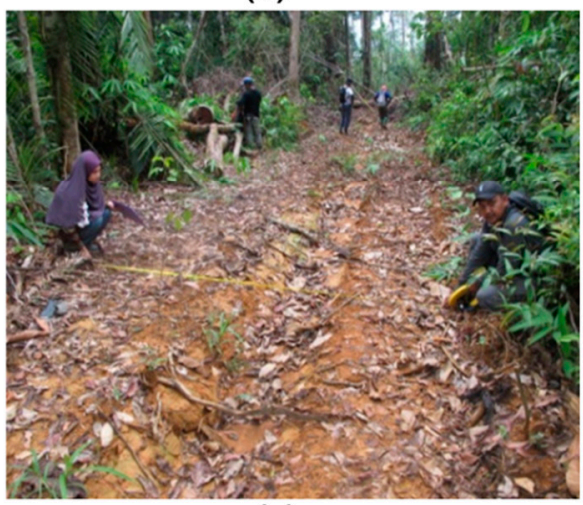

(c)

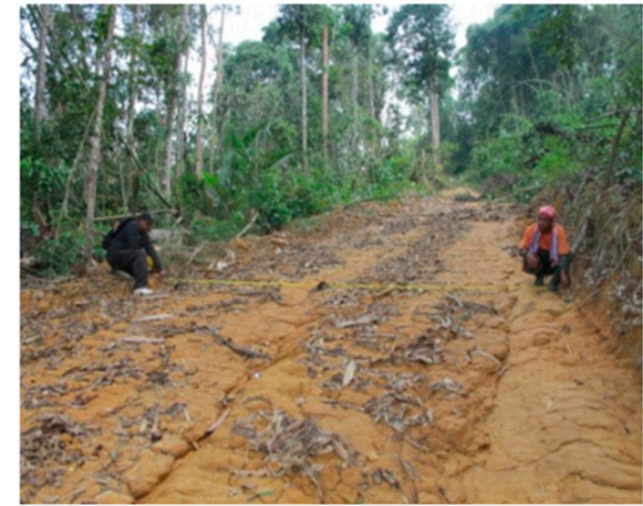

(b)

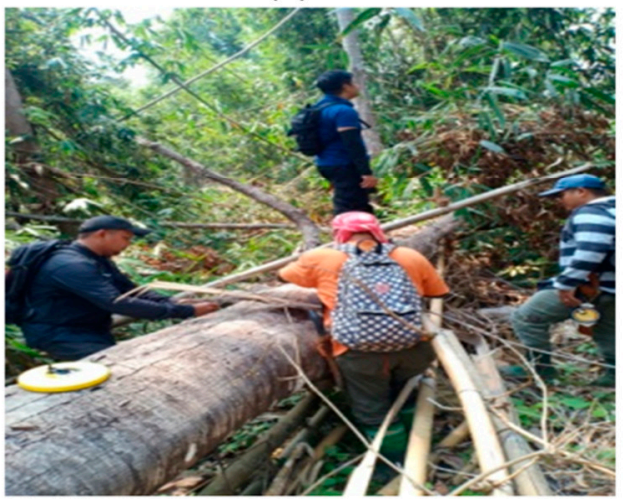

(d)

Figure 3. Example of the fieldwork methodology: (a) DBH measurement using tape diameter measured on tree stump; (b) measurement of length and width of logging roads; (c) measurement of length and width of skid trail; and (d) measurement of diameter, length and the cross-sectional areas of felled $\log$.

\subsection{UAV Data RGB Acquisition and DSM and DTM Data Processing}

The ortho-photo were georectified with WGS84 as the datum, using the Geographic Longitude and Latitude Projection. The UAV image has a resolution of $0.0631 \mathrm{~cm}$ and a point density of 251 points per $\mathrm{m}^{2}$ after processing. After geometrically correcting with GCP points, the overall accuracy was $3.6 \mathrm{~m}$. The analysis in this study was done utilising multi-bands of red, green and blue (RGB). When compared to using a single band, these bands tend to improve classification accuracy. DJI Phantom 3 Advance (Table 1) was used to fly across the research region within the field collection duration on the ground, with a spatial resolution of $0.06 \mathrm{~m}$. The UAV was flown from an open area near the research site, approximately in the middle of the scene. Due to the topographical conditions in the research location, which is not a flat area, the flight front lap was $75 \%$, and the side overlap was $89 \%$. The flying height was modified to $90-110 \mathrm{~m}$ above ground level.

Table 1. DJI Phantom 3 specification.

\begin{tabular}{cc}
\hline Acquisition Date & August 2019 \\
\hline Sensors: & $1 / 2.3^{\prime \prime}$ CMOS effective pixels $=12.4 \mathrm{M}$ \\
(total pixels $=12.76 \mathrm{M})$ \\
Lens & FOV $94^{\circ} 20 \mathrm{~mm}(35 \mathrm{~mm}$ format equivalent $\mathrm{f} / 2.8$ focus at $\infty$ \\
Max Flight Time & Approx. 23 min \\
Satellite Positioning Systems & GPS $/$ GLONASS \\
Image Size & $4000 \times 3000$ pixels \\
\hline
\end{tabular}


Using Agisoft Metashape Profesional Software, all images captured from the UAV were transferred and processed. The quality for this selective logging region was set to high, with an aggressive depth filtering set. Therefore, the imagery's quality was sharpened, and more points clouds were created. The polygonal mesh model was created after the photo-alignment process using point cloud information imported from depth map data. The face count specifies the maximum number of polygons in the final mesh. Values were chosen as high, which provides a higher number of polygons for a mesh of a certain level of complexity. The Ulu Jelai UAV depth map parameter quality was set to ultra-high The quality parameters are interpreted in the same way as the accuracy choices in photo alignment. Thus, this selective logging region's quality was set to high, with aggressive depth filtering.

The next process is generating a dense point cloud based on the computed exterior and interior image orientation parameters. The depth maps were used to generate dense point clouds. The number of contributing depth maps is extracted and stored as a confidence value for each point in the final dense point cloud. Using the filter by confidence function, this confidence value was utilised to filter low confidence points further. This process generated 430,152,544 dense point cloud data, with point colours divided into three bands. To eliminate non-ground points, a process is known as ground filtering was applied. This approach utilises a sparse triangulation that is generated from seed points and densified iteratively. DTMs can only be created using dense point cloud data that has been categorised into ground points and other semantic classes prior to the DTM production stage. The ground filtering method used to classify ground points is modified from the adaptive triangular irregular network (TIN) surfaces technique. Then the DTM were exported from DSM solely based on ground points. The next stage focuses on creating an ortho-mosaic RGB image, with pixel sizes proposed based on the source photos' average ground sampling resolution. The orthomosaic UAV and the GCP points were overlayed with each other (Figure 4). Thereafter, the final product is exported as an export ortho-photo picture (Figure 5a). The outputs of DSM and DTM are shown in Figure 5b,c.

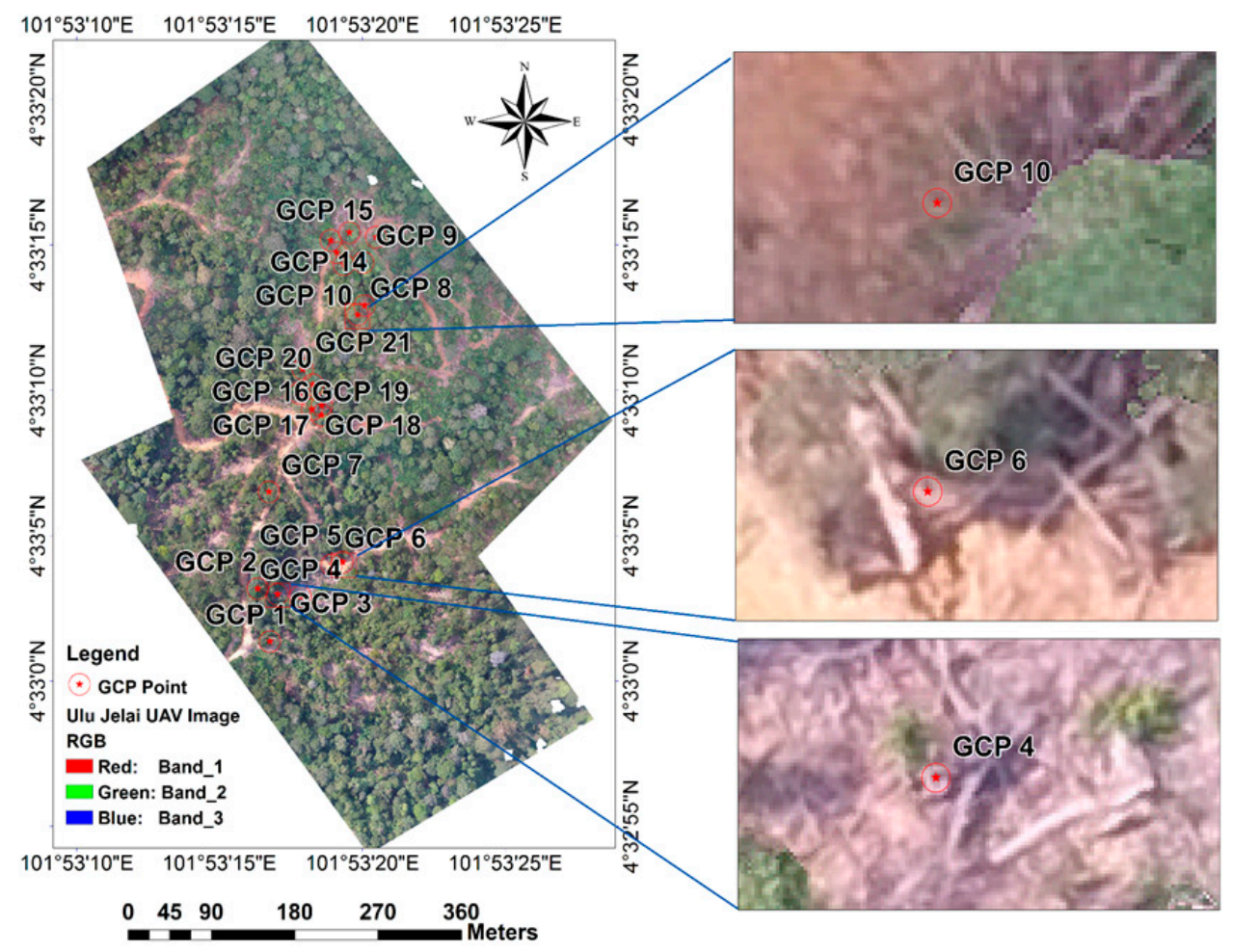

Figure 4. Ground control points distribution over UAV image in Ulu Jelai forest reserve. 


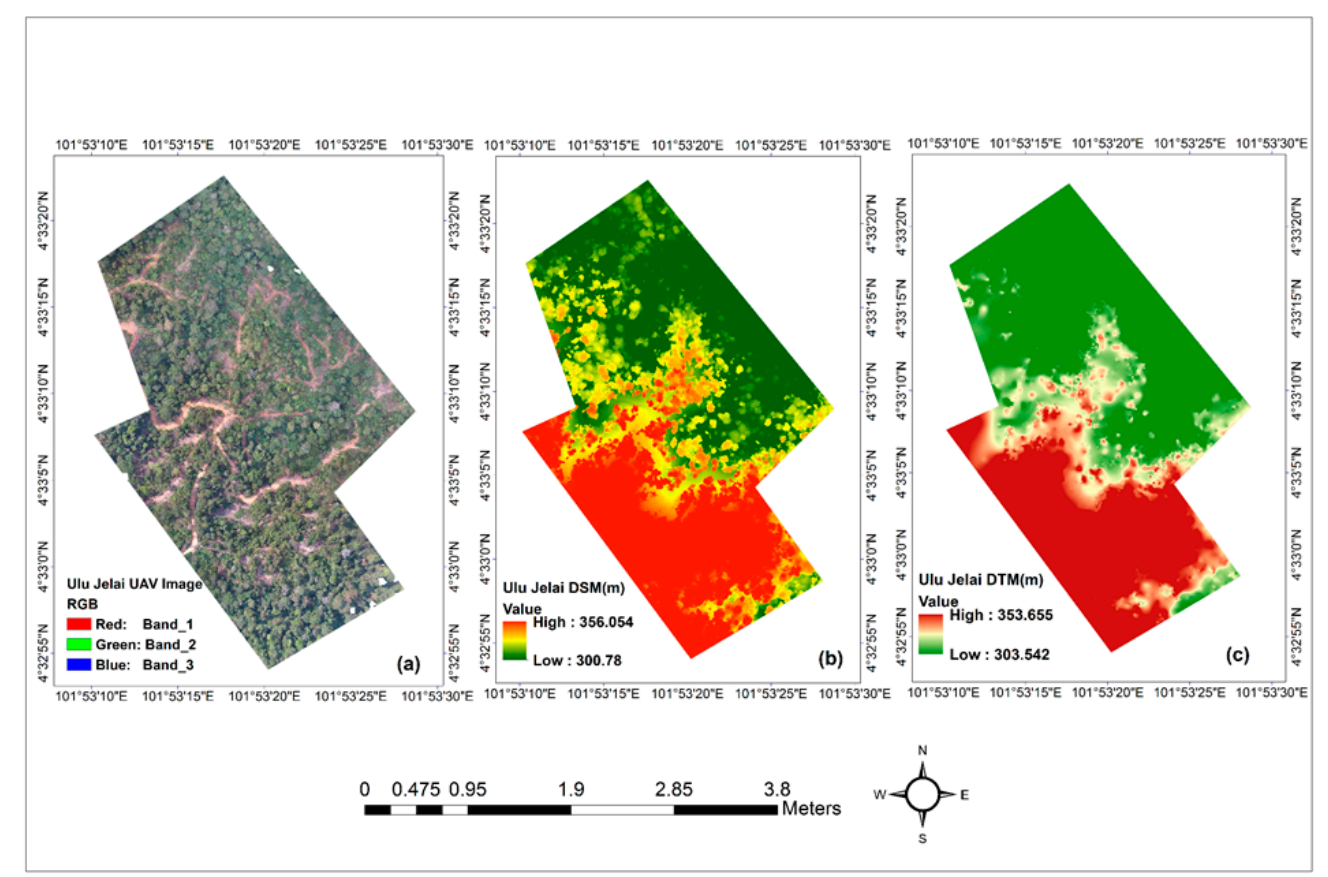

Figure 5. Types of data used in this study over Ulu Jelai forest reserve: (a) Very high-resolution image of UAV red green blue (RGB); (b) digital surface model (DSM); and (c) digital terrain model (DTM).

\subsection{Integration of Template Matching and Object-Based Image Analysis for Stump Detection}

Since the size of the individual stump is between 0.5 and $1.5 \mathrm{~m}$, an automated object identification approach is required in the initial phase to identify them from the UAV image. The stump derived from the integrated object detection technique will subsequently be utilised as an ROI for classification and the ROI of additional logging indicators, so that it may be detected, mapped, and the accuracy of the automated method improved, rather than spending time digitizing from the UAV. Two methods were used in object detection: OBIA and TM with OBIA.

The degree of similarity between the images and the feature can be assessed by using the TM method. The algorithm developed in TM will find the pattern and shape of an object which is the tree stump. First, many templates in the original image were identified and saved in a database. An optimal template was chosen based on an iterated approach in order to achieve high-quality tree identification. Second, these templates were classified into three classes, correct, unclassified and false. The visual analysis assigned the templates to these three levels. The TM algorithm recognised the position of stumps inside a layer with the maximum threshold value, as shown by the chosen stumps with the correct attribute. Furthermore, using a trial-and-error technique, the threshold (T) of 0.6 and layer two were chosen to produce a point shapefile that represented the best stump (Figure $6 \mathrm{~b}$ ). These data were exported into GIS software and the stumps will be used as a training sample for the classification.

The eCognition Developer 64 software was utilised to perform the segmentation, which made use of spectral bands in red, green, and blue (RGB) to aid the process. Stump detection can be affected by a combination of factors in the UAV imagery. By using a multi-resolution segmentation technique, it decreases the average uncertainty inside an image object. This study used the estimate of scale parameter (ESP) technique, estimator shape, and compactness to represent the stumps from the scale parameter as objects. The ESP tool computes the local change and rate of change in each dimension and allows the user to figure out what scale the image can be segmented to improve feature extraction. Figure 6a summarises the multiresolution segmentation slgorithm findings for the Ulu Jelai research region, as well as the parameters applied. The three weights of shape and compactness, as well as the scale, were the MSA criteria. As a result, the shape was set to 
0.1 and the compactness to 0.5 . Finally, a scale of 20 was used for the stump detections, with the segmentation output details segmented and the precise features polygons segmented as shown in Figure 5a. These values were chosen because they provide an appropriate description of a single stump. The tree stump detection was then assessed by comparing it to tree stumps that had been measured in the field. If a segmented polygon was within $0.5 \mathrm{~m}$ of a field-measured stump, it was considered a correct match. The overall accuracy of the segmentation, as well as the omission and commission error, were evaluated. In this study, the stump that was detected automatically was assessed and compared with 21 field data on the ground.

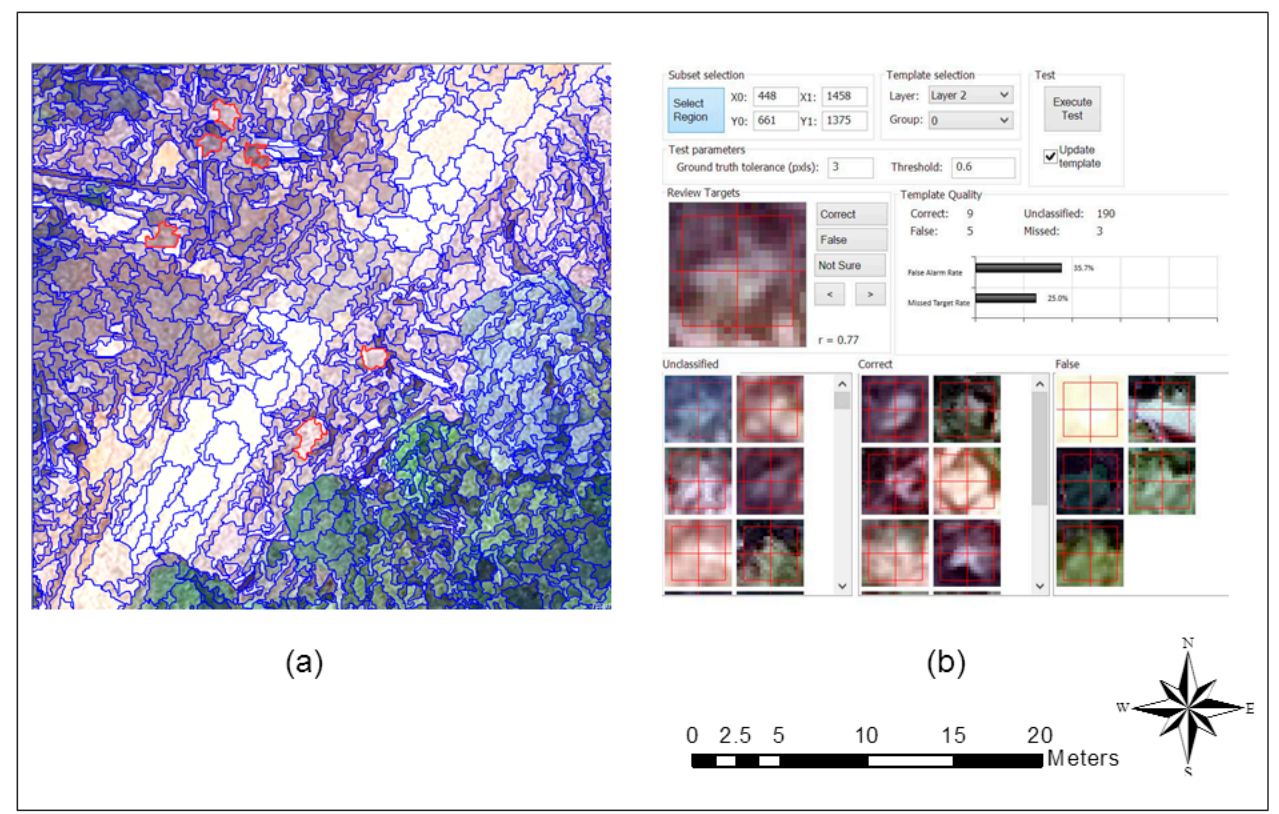

Figure 6. Methods of integrating OBIA and TM. (a) Detail of scale in OBIA; (b) sample of TM searching.

\subsection{Training Datasets}

Region of interest (ROI) or training samples was established by choosing one or more polygons for each class. The stumps attributes extracted from the integrated TM and OBIA methods were then selected as input in the classification. In eCognition, vector systems are utilised for sophisticated categorisation as well as import and export. In ENVI 5.2 software, the stump characteristics were exported to a polygon shapefile and transformed to an ROI for the training courses, along with other classes created with ROI tools. Therefore, the machine classifier and other classifiers can be used for all the combinations of classes. The classifier with the highest accuracy will be chosen and compared to other non-parametric advanced classifiers such as machine learning and traditional supervised classification methods in forestry applications. The consistency of the training area and how effectively it represents the same class throughout the image are essential aspects to consider when choosing a decent training location for a class [21,22]. For each class, these training pixels provide values from which to estimate the mean and covariances of the spectral bands used. This information is to be used by all the classifiers to assign pixels to a particular class. For Ulu Jelai, nine ROIs were classed as classes consisting of tree stumps, main road, skid trail, fell log, felled trunk, forest, objects (car), dead trees and no pixel (Figure 7). After selecting the training data classes, machine learning and conventional method classification were run, and the output and accuracy reports were assessed. 


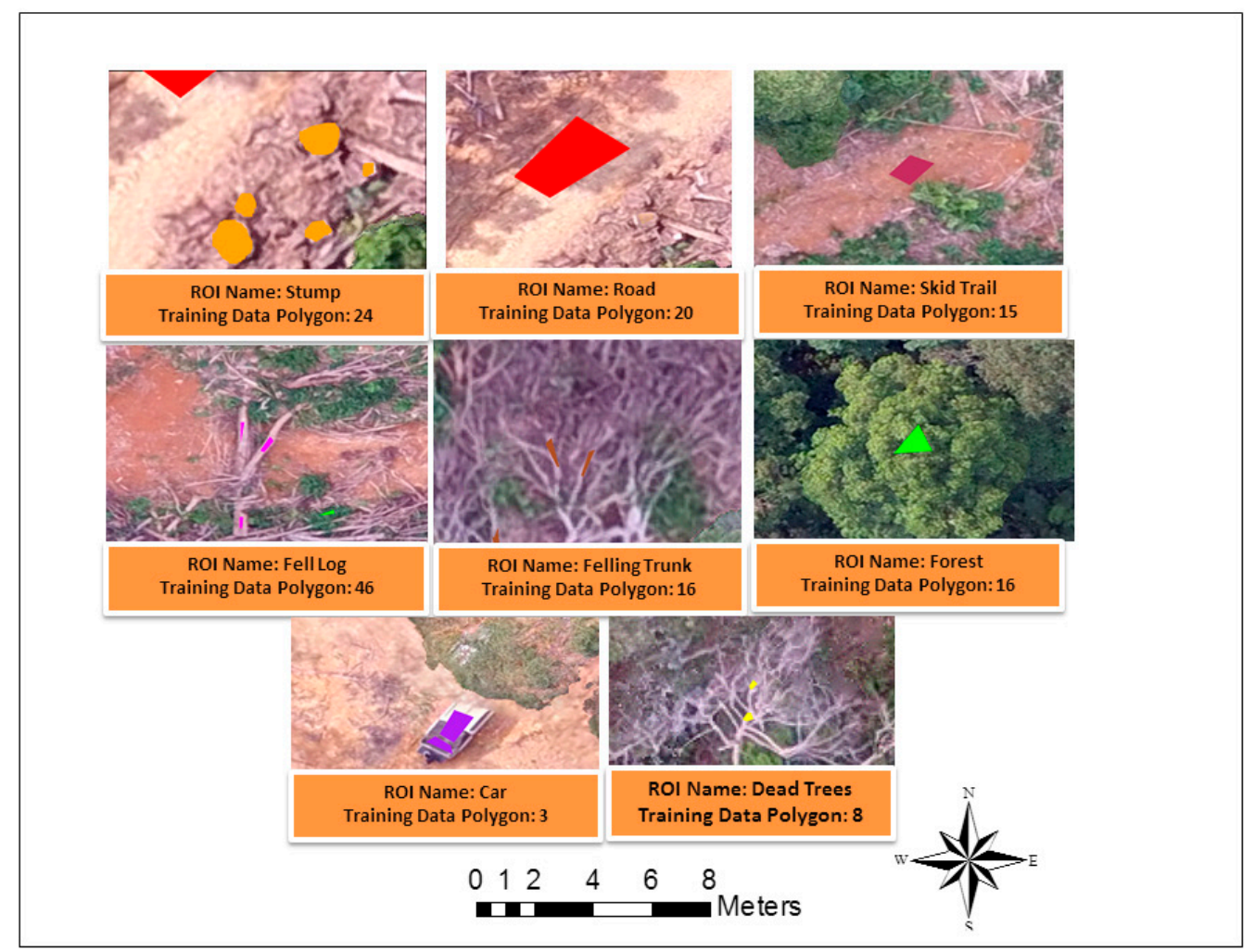

Figure 7. Collecting training samples by regions of interest that represent stump, road, skid trail, felled log, felling trunk, forest, objects (car) and dead trees in Ulu Jelai forest.

\subsection{Image Classification Process}

Machine Learning and Conventional-Based Classification

Artificial neural networks (ANNs) are the types that are commonly used to classify remote sensing data and are being used to improve the classification accuracy of remote sensing data. The capability to estimate non-linear functions and identify complex relationships in data sets are instrumental attributes that could help the process field of remote sensing. An input layer, an output layer, and at least one hidden layer makes up a typical propagation network. For supervised learning, ENVI software's neural network method utilises conventional backpropagation. Support vector machines (SVMs) are a highly advanced type of machine learning based on a strong computational basis. It has a strong analytical ability to solve non-linear high dimensional and minimal sample problems. Polynomial and radial basis function (RBF) kernels are the most commonly used functions for classifying remotely sensed data. RBF is computationally fast and easy to implement and requires optimizing only two parameters in ENVI Software. These are the penalty parameter for standardizing the error of misclassified data points in the training dataset samples, and gamma $(\gamma)$, which is the kernel width parameter of the RBF [23]. Using textural features in ANN helps solve misclassification, while SVM can accommodate strong-dimensional data sets [24].

In this study, the UAV images were subjected to ANN classification in the first phase by providing training sites inputs that provide pre-expertise of the study region. ANN classification was performed using ENVI 5.2 software. Herein, a neural network with seven hidden layers and a training rate of 0.2 was considered to be adequate to show the classification output. Then the performance was compared in three iterations of 500, 700 and 1000 as an evaluation for the best output (Table 2). The penalty parameters were set to 100 and $\gamma$ parameters of 0.25 for the RBF kernel (Table 3). The training dataset was divided into nine classes of the same ROI produced during the initial process. 
Table 2. The combinations of parameters for the artificial neural network.

\begin{tabular}{cccc}
\hline & $\# \mathbf{1}$ & $\# \mathbf{2}$ & $\# \mathbf{3}$ \\
\hline Number of hidden layers & 7 & 7 & 7 \\
Training rate & 0.2 & 0.2 & 0.2 \\
Number of iterations & 500 & 700 & 1000 \\
\hline
\end{tabular}

Table 3. The parameter used for SVM.

\begin{tabular}{ccc}
\hline & Penalty Parameter & Gamma in Kernel Function \\
\hline SVM & 100.00 & 0.25 \\
\hline
\end{tabular}

Three types of traditionally-based classifications were employed and compared to machine learning classifications. One of the most common supervised classification methods for remote sensing image data is maximum likelihood. According to [25], this technique is based on the chance that a pixel belongs to a specific class. It requires the least amount of time to calculate when compared to other supervised algorithms, but it ignores class variability and only classifies pixels that should not be unclassified. In multiple feature sets, the minimum distance classifier is used to classify unknown picture data into classes by minimising the distance between the image data and the class [26]. The Mahalanobis distance classifier sorts' data into distinct sets in the same manner as the minimum distance classifier does. The covariance matrix for classification is not recognised in such a minimal distance clustering technique, but the covariance must be obtained in the Mahalanobis distance classifier [27].

For the classification performance used in this study, all classification accuracies were assessed on a pixel-by-pixel basis. Some pixels representing each class were randomly picked from the UAV maps and used to evaluate the accuracies of the five types of classifiers using a stratified sampling approach. The kappa metric was used to examine the accuracy of a system and corrects some of the discrepancies across matrices. The categorisation was re-evaluated using ground sample data to improve the accuracy. LACO-Wiki (http: / / www.laco-wiki.net/, accessed on 30 June 2021), a web-based validation tool, was used to assess the best classification results [4]. The LACO-Wiki application provides an online platform for assessing map accuracy and sharing automated maps and reference material such as satellite photos and Google and Bing maps [28]. The validation samples were limited to regions with high-resolution images $\left(5 \mathrm{~m}^{2}\right)$ to guarantee that the consequences of selective logging impacts could be readily detected. Within the research region and within a $1 \mathrm{~km}$ radius of the logging region, 30 validation points were randomly picked for each map. The buffer zone was established to ensure that sample locations eligible for selective logging affects characteristics were evaluated in close proximity, which helped to prevent inflating the accuracy estimations.

\subsection{CHM, Logging Gaps and Canopy Cover Loss}

Dense cloud points classification allows specifying which types of objects in a scene should be reclassed by providing the relevant point class as a mesh generation source data. In this situation, mesh reconstruction was based solely on ground points, allowing for the creation of a digital terrain model (DTM) (as opposed to a digital surface model (DSM), which were based on the entire dense point cloud). By removing non-ground pixels that had previously been categorised using the software's automatic classification procedure and manually subtracting the classes, DTM was inferred from the 3D scene. Orthomosaic, DSM and DTM data were saved as raster files, then processed with ArcGIS software. A pixel reduction from the height of the DTM layer to the height of the DSM layer produces the CHM (Canopy Height Model) raster layer. (Figure 8a) depicts the canopy height model for the specified logging region. 


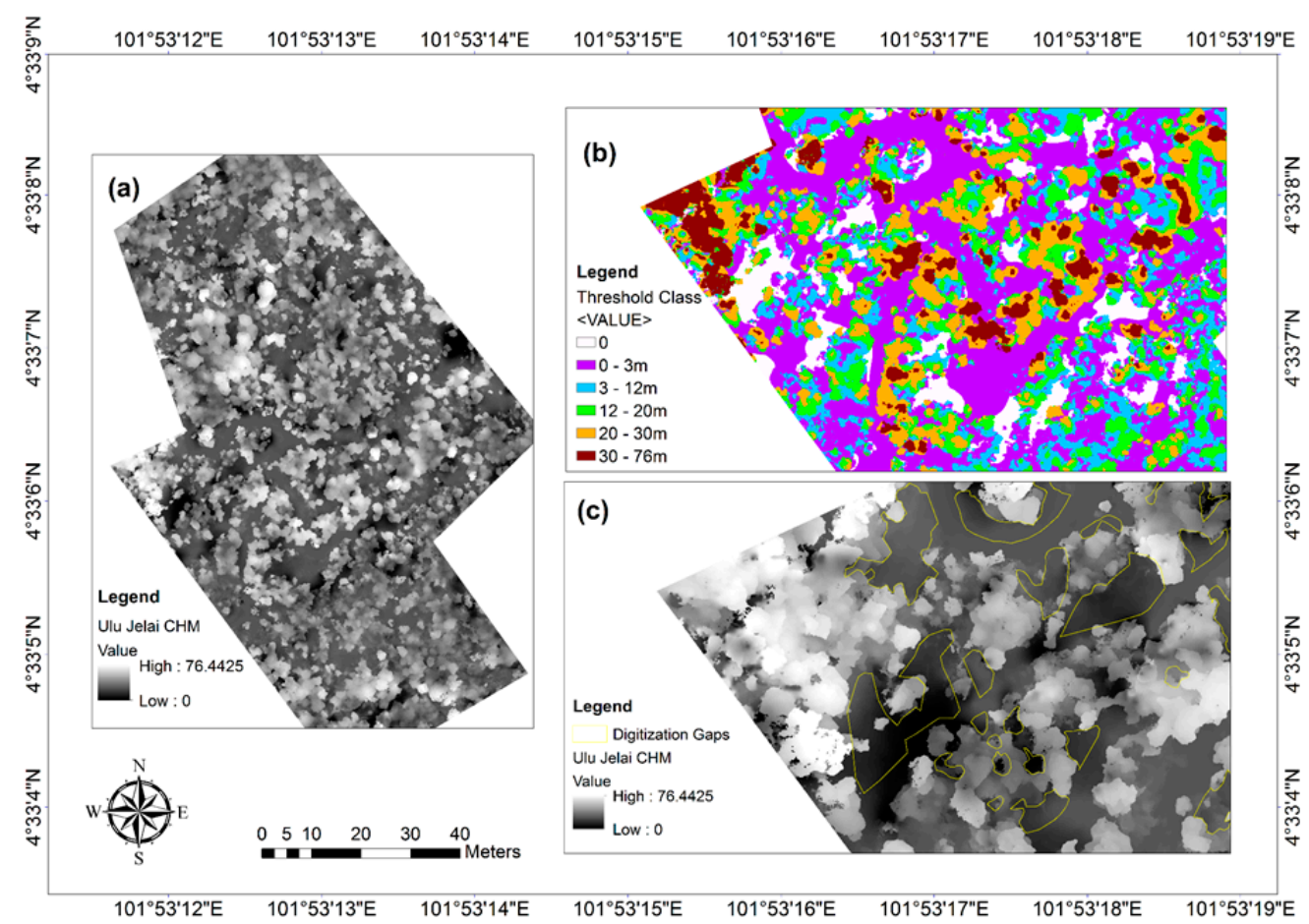

Figure 8. Sampling design of canopy gap datasets: (a) CHM; (b) CHM height classes; and (c) forest gap digitization.

Forest gap extraction using the CHM (Figure 8a) was done in three phases in ArcGIS 10.3 (raster and vector-based), which includes the identification of logging gaps and dense forest, classification of the dense forest into height classes from low to high in elevation and, finally, gap extraction in certain classes [20]. Gaps, roads and skid trails were identified in addition to the post-selective logging detections. Therefore, in this study, the classes produced below $3 \mathrm{~m}$ were identified as class 2 and 3 out of 6 classes (Figure $8 \mathrm{~b}$ ). The manual digitization of disturbances in the whole region covered by UAV flights was quantified, and the findings were compared to an automated technique that was described by [6]. For the detection of the selective logging impacts, the digitization was done using a high-resolution RGB orthophoto mosaic (roads, felled log, canopy gaps and skid trails). The sampling design of digitization is shown in Figure 8c.

To automatically detect forest canopy gap, we adapted a gap definition similar to [20] in which, canopy gaps are openings in the forest canopy extending down to an average height $\leq 2 \mathrm{~m}$ above ground [29]. Logging gaps were defined by a low height threshold $(\mathrm{CHM}<3 \mathrm{~m})$. The $3 \mathrm{~m}$ threshold was used to allow the inclusion of the felled tree crowns on the ground as gaps.

\section{Results}

\subsection{Integration of TM and OBIA Results on Stump Detection}

The results of the automated approach from the integrated template matching and multiresolution segmentation algorithm run by eCognition Developer $\times 64$ software are presented below.

\subsubsection{Results of Both TM and OBIA}

The actual image of the tree stumps was detected in the UAV image by using the integrated (TM) and OBIA method (Figure 9). Based on the first evaluation, the results are more accurate than those produced by a single OBIA technique; in this case errors in the OBIA technique were minimised. It can be seen that the stumps which were represented by more blue shape-files in the (TM) method were accurately counted. However, in densely forested regions, the integrated method revealed certain limits. Some of the stumps beneath 
the research area's forest canopy, for example, were not discovered. This shows that most of the stumps and logs were easily detected with the selected target and scale. Therefore, the stump-exported polygons were selected as training data in the classification process after the segmentation process was executed. For the classification, the exported polygons were then used as the ROI.

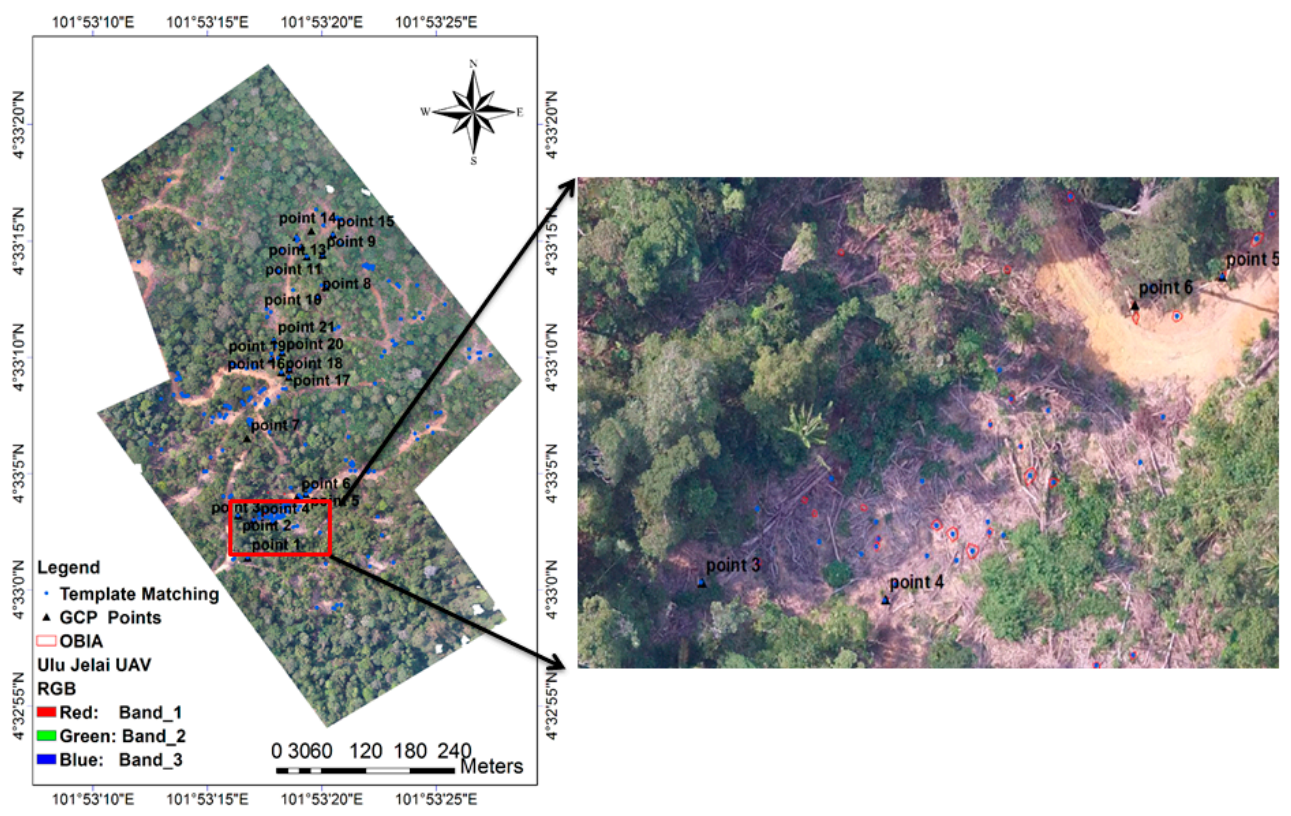

Figure 9. Map of stumps detection by using integration of TM and OBIA approach.

\subsubsection{Accuracy Assessment on the Stump Detection}

Tables 4 and 5 show the accuracy evaluation of OBIA and integration of TM and OBIA. Tree stump detection using the integration of TM and OBIA methods gives an overall accuracy of $85.7 \%$ in compartment number $159,75 \%$ in compartment 124 and $66.7 \%$ in compartment 160 (Table 5, Figure 10). The errors of omission are reduced from compartment numbers 160 to 159, respectively. Among the 21 stumps measured on-site, 16 stumps were detected from the automated approach. The total overall accuracy measured in these three compartments is $75.8 \%$ by using the integrated TM and OBIA compared to OBIA method only at $66.9 \%$. Tree stumps detection using the integration of TM and OBIA gives the highest accuracy. Because some stumps were positioned below the forest canopy and the field data collection was done six months after logging, the accuracy result was still moderate.

Table 4. Error matrix for stump detection by using OBIA.

\begin{tabular}{ccccccc}
\hline $\begin{array}{c}\text { Compartment } \\
\text { (No) }\end{array}$ & $\begin{array}{c}\text { Measured } \\
(\mathbf{n})\end{array}$ & $\begin{array}{c}\text { Detected } \\
\mathbf{( n )}\end{array}$ & $\begin{array}{c}\text { Omitted } \\
\mathbf{( n )}\end{array}$ & $\begin{array}{c}\text { Overall } \\
\text { Accuracy (\%) }\end{array}$ & $\begin{array}{c}\text { Omission } \\
\text { Error (\%) }\end{array}$ & $\begin{array}{c}\text { Commission } \\
\text { Error (\%) }\end{array}$ \\
\hline 159 & 7 & 5 & 2 & 71.43 & 28.57 & 40.00 \\
124 & 8 & 5 & 3 & 62.50 & 37.50 & 60.00 \\
160 & 6 & 4 & 2 & 66.67 & 40.00 & 50.00 \\
& & Overall & $66.87 \%$ & \\
\hline
\end{tabular}

Table 5. Error matrix for stump detection by using integrated TM and OBIA.

\begin{tabular}{ccccccc}
\hline $\begin{array}{c}\text { Compartment } \\
\text { (No) }\end{array}$ & $\begin{array}{c}\text { Measured } \\
\text { (n) }\end{array}$ & $\begin{array}{c}\text { Detected } \\
\text { (n) }\end{array}$ & $\begin{array}{c}\text { Omitted } \\
\text { (n) }\end{array}$ & $\begin{array}{c}\text { Overall } \\
\text { Accuracy (\%) }\end{array}$ & $\begin{array}{c}\text { Omission } \\
\text { Error (\%) }\end{array}$ & $\begin{array}{c}\text { Commission } \\
\text { Error (\%) }\end{array}$ \\
\hline 159 & 7 & 6 & 1 & 85.71 & 14.29 & 16.67 \\
124 & 8 & 6 & 2 & 75.00 & 25.00 & 33.33 \\
160 & 6 & 4 & 2 & 66.67 & 33.33 & 50.00 \\
& & Overall & 75.79 & \\
\hline
\end{tabular}




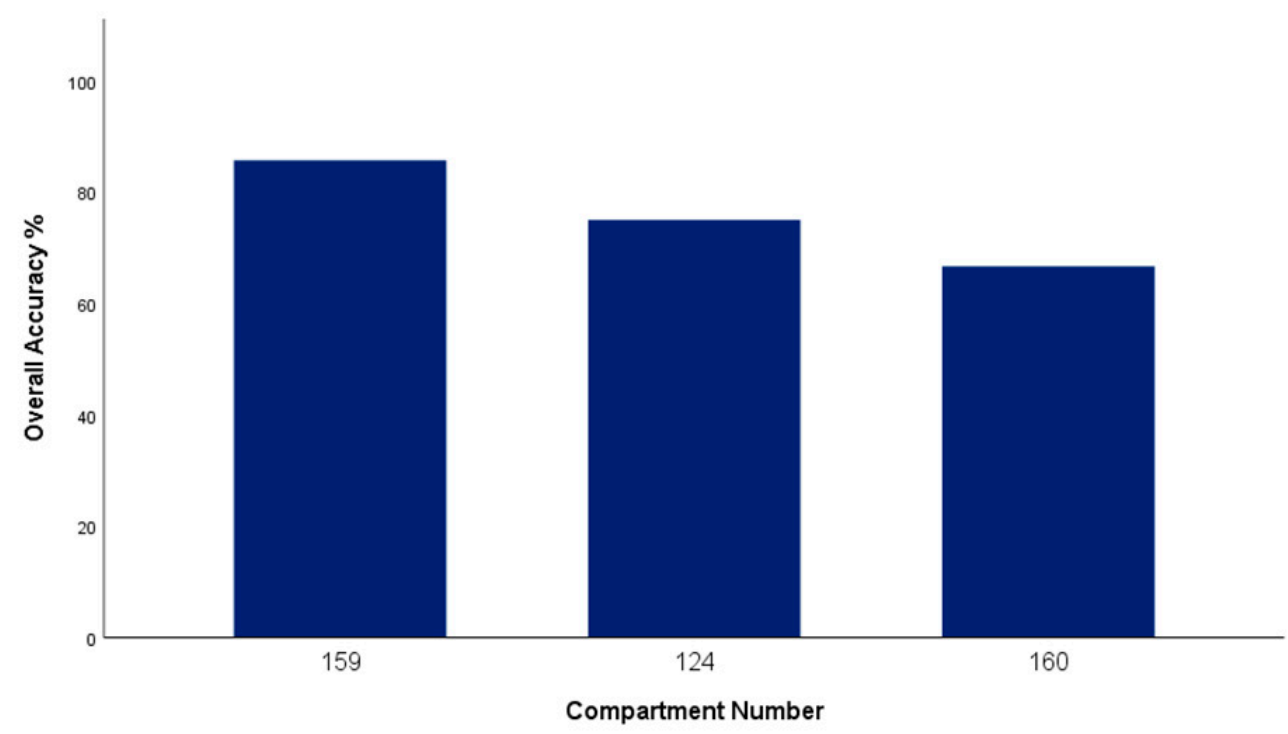

Figure 10. Overall accuracy of the stump detections by using integrated TM and OBIA method.

\subsection{Density Mapping of the Stump Detections}

The orthomosaic was produced with ArcGIS 10.3 software, and the location of the segmented stump in points, polygons, and GCP points data was mapped (Figure 6). Density mapping of the stump's detection is simply a way to show where the identified points were concentrated in this study area. Figure 11 illustrates a map that uses interpolation methods to predict where the concentration of a particular feature may be throughout a given surface. The red colour in Figure 6 shows that the concentration of stumps was high, mostly in the centre of the images, and it also shows that selective logging was conducted along the main roads. The lowest value of stumps shown in blue colour was detected far from the main road. This is a good example of a secondary analysis from the study that could be used to further determine the nature and dynamics of tree stump distribution.

\subsection{Performance of Machine Learning and Conventional Classifications}

\subsubsection{Artificial Neural Network Classification (ANN)}

In this study, a neural network with one hidden layer failed to show the classification output, so a neural network with seven hidden nodes was chosen, and there was three types of iterations that were being compared while running the performance of ANN classification, which are iterations of 500 (Figure 12a), Iterations of 700 (Figure 12b) and Iterations of 1000 (Figure 12c). In the below three maps of ANN Classifications output, there were still unidentified features using the ANN Algorithm, although the training sites were collected from all classes in the preliminary training data.

\subsubsection{Support Vector Machine (SVM) Classification}

The SVM classification algorithm was applied to the UAV image based on the training patterns and the reference materials determined in the second phase. The same training sites were used for comparative study of each system. The corresponding ENVI software package module was utilised, and the image output is shown in Figure 13, respectively. In SVM implementation, choosing a kernel function and kernel-specified parameters and parameter values that influence the trade-off between increasing the margin and reducing the training error is crucial, depending on the given dataset. Four kernels are being used and compared in SVM Classifiers: Radial basis function, linear, polynomial, and sigmoid. Radial Basis and polynomial kernel functions are the most commonly used in remote sensing image classification (RBF). In this study, the radial basis function algorithm was implemented due to the higher accuracy than the other parameters that were being run. Based on SVM method, all feature classes were identified within the ROI during the classification process at the earlier stage. 


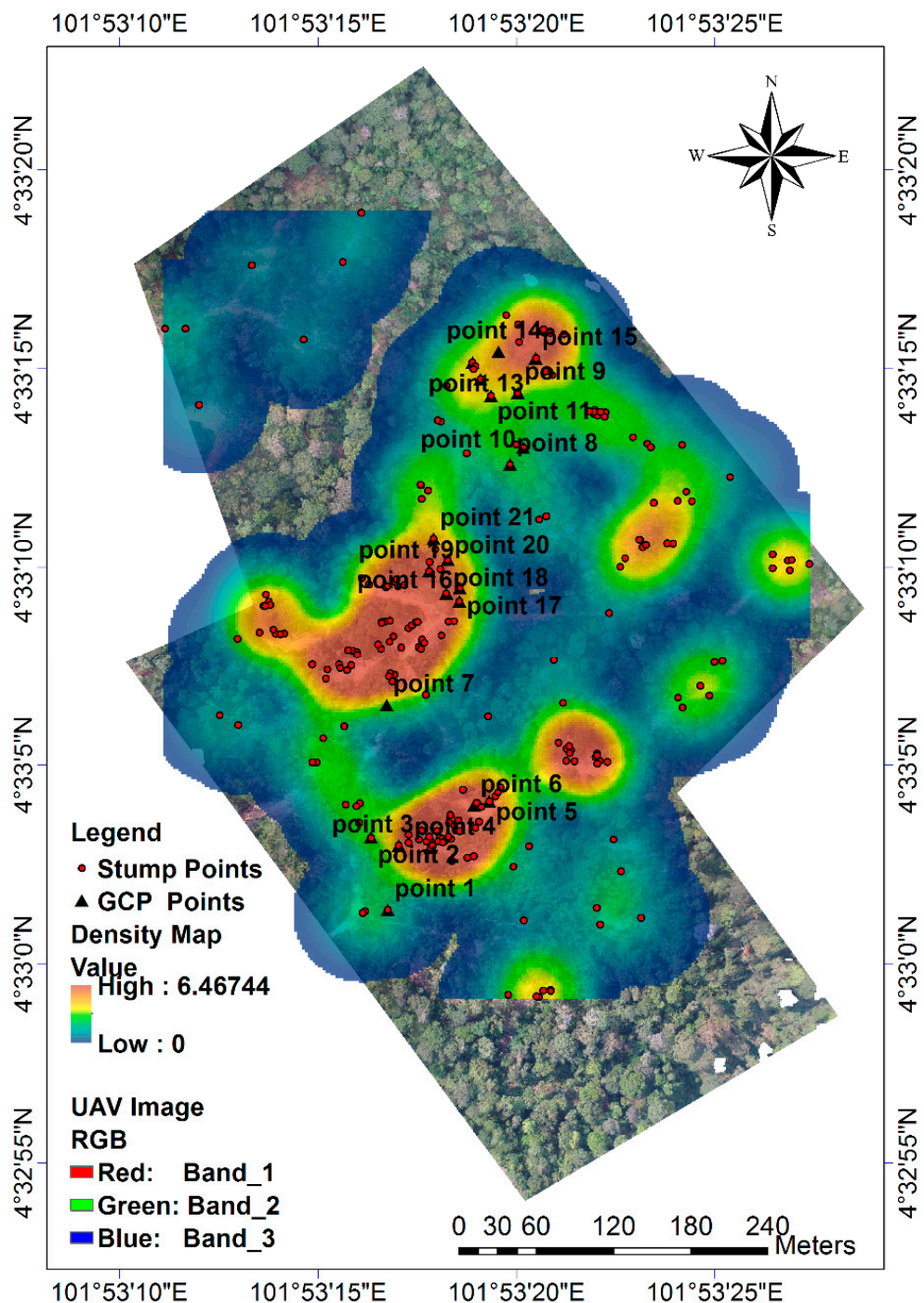

Figure 11. Stump detection density map using the integrated TM and OBIA approach with kernel density. The warmer colour reflects regions with dense stumps, whereas the cooler colour depicts areas with fewer stumps.

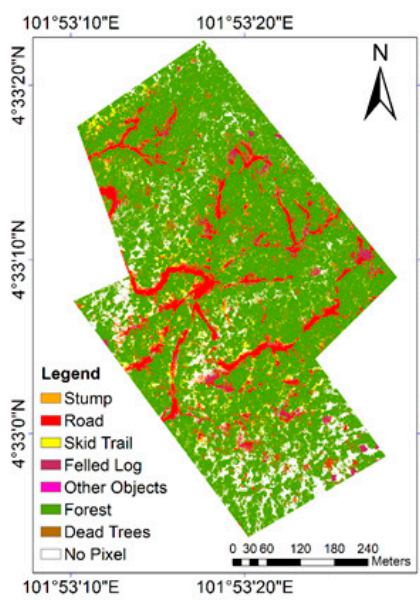

(a)

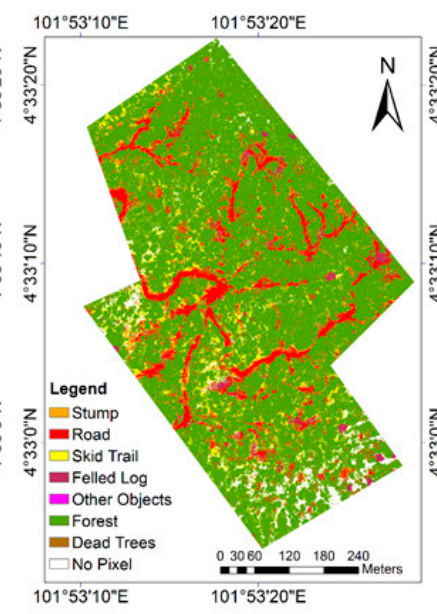

(b)

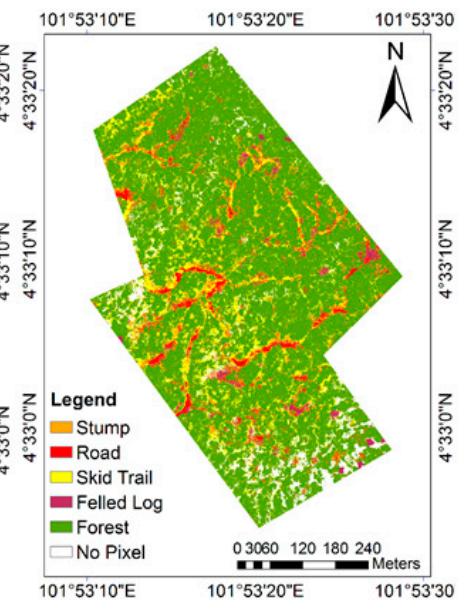

(c)

Figure 12. Classified ANN maps showing all the impacts of selective logging over Ulu Jelai Area with (a) 500 iterations; (b) 700 iterations; and (c) 1000 iterations. 


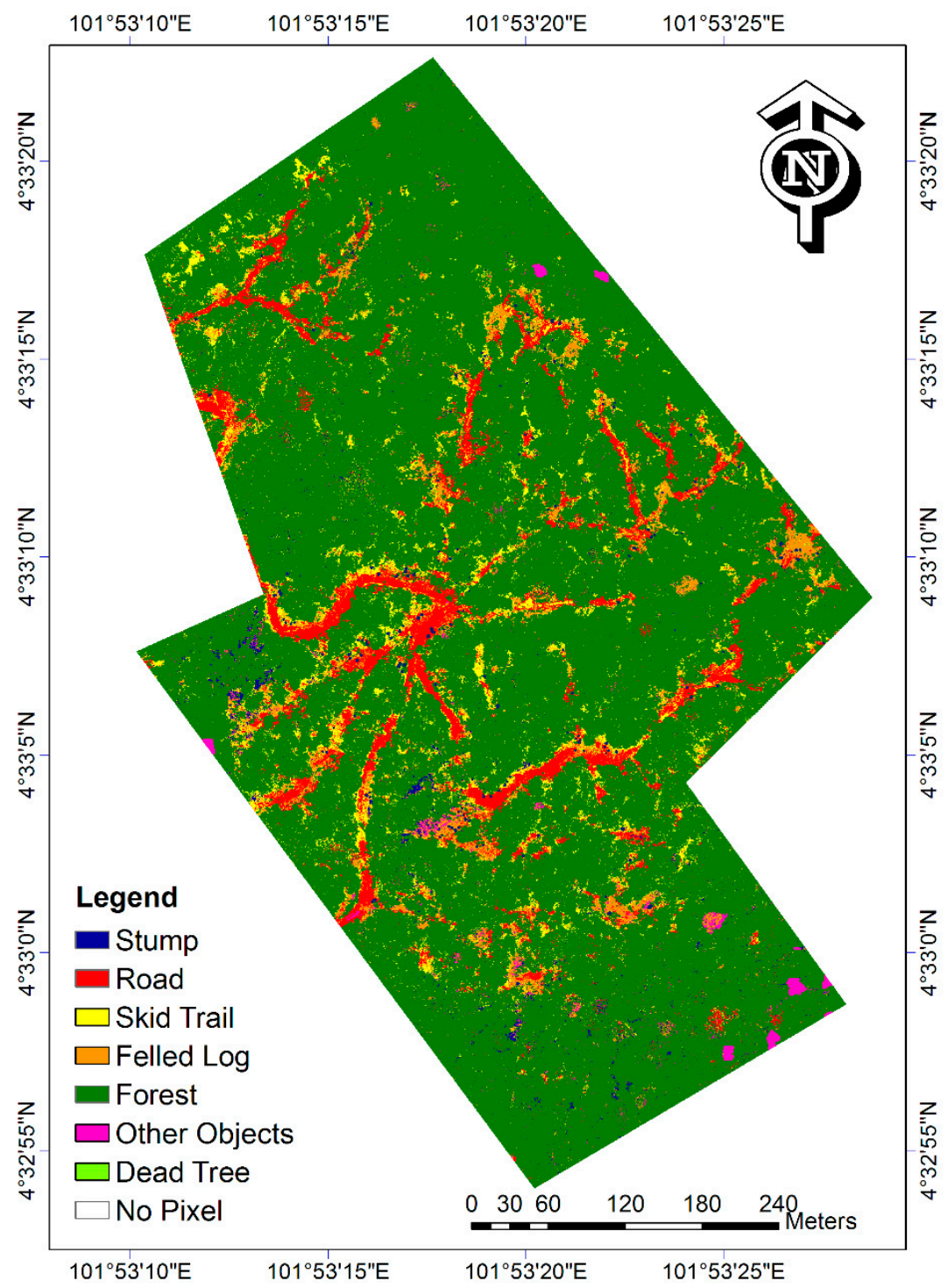

Figure 13. Classification map of selective logging indicators using SVM method.

\subsubsection{Conventional Classification Methods}

Three different conventional classifications methods were run to perform the image classification results and accuracy performance: Mahalanobis distance, maximum likelihood and minimum distance classifier. These three classifications were established based on areas that allowed for simple and visual interpretation. Figure 14 shows the comparison of conventional classification methods in the Ulu Jelai Area. It can be noticed that both maximum likelihood (Figure 14a) and Mahalanobis distance (Figure 14b) methods agreed with the selective logging impacts classes selected. Their predictions of roads, skid trails, felled logs, and forest were very reasonable. However, the minimum distance (Figure 14c) method overestimates all the classes except for the road in Ulu Jelai.

Classification accuracy refers to the level of agreement between the specified reference materials and the classified data. A series of reference pixels is typically used when points on a classified image for which actual data is identified. For this purpose, 70.543-pixel polygons in the study were randomly selected, and their agreement with ground truth was analysed. Table 6 shows the overall percentage accuracy values and kappa coefficients. The overall accuracy for maximum likelihood and Mahalanobis distance classification methods were comparable with $59.79 \%$ and $55.94 \%$ accuracy differs to the minimum distance which reported accuracy at only $47.30 \%$. While for the machine learning classification, artificial neural network methods were significant with 500 iterations and seven hidden nodes with 
a smaller scale and higher resolution. In general, the fewer the iterations being used, the length of processing time will be shortened. Hence the result of 500 iterations of $79.83 \%$ shows the highest accuracy between these three ANN parameters. The comparison was made to find the best ANN classification parameters, and 500 iterations, were acceptable to use for the UAV imageries. In this study, support vector machine performed superior to others, with an accuracy of more than $80 \%$, followed by ANN as the second highest, with an accuracy of more than $70 \%$ and minimum distance to be the lowest among the statistics with an accuracy of $47 \%$ (Table 6, Figure 15). The three tested neural network classifiers showed nearly similar trends. This indicates that machine learning classification methods performed better than the other classifiers for the selective logging impacts study in a forested area.

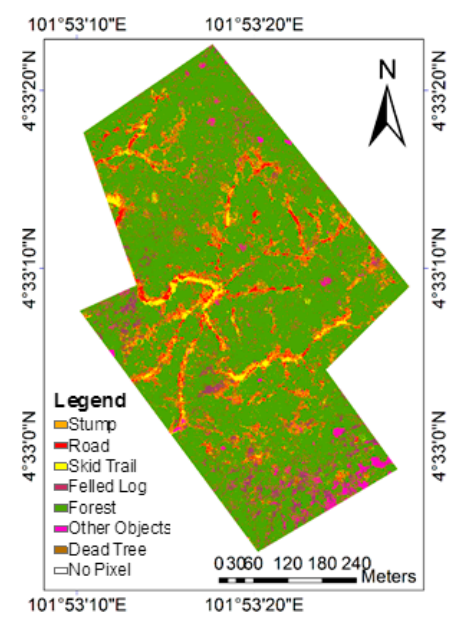

(a)

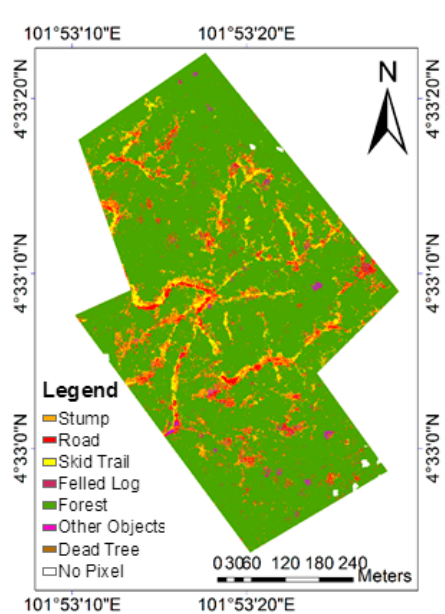

(b)

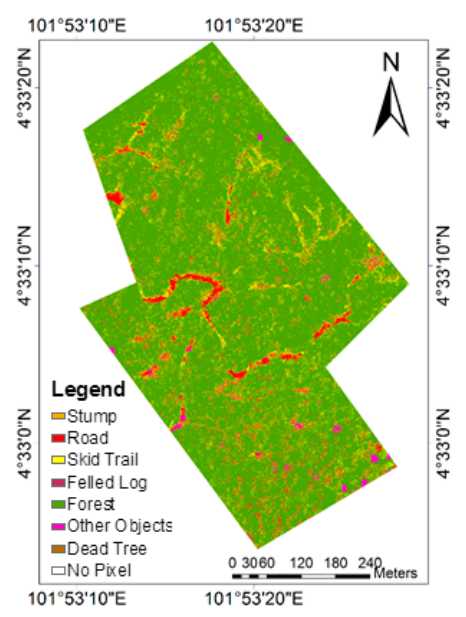

(c)

Figure 14. Maps of conventional classifications using three different methods: (a) Mahalanobis distance; (b) maximum likelihood; (c) minimum distance.

Table 6. Overall accuracy and kappa coefficients from the classifications.

\begin{tabular}{ccc}
\hline & Overall Accuracy & Kappa Coefficients \\
\hline Maximum Likelihood & $59.79 \%$ & 0.47 \\
Minimum Distance & $47.30 \%$ & 0.30 \\
$\quad$ Fuzzy C Means & $55.94 \%$ & 0.40 \\
- Mahalanobis Distance & & \\
$\quad$ Neural Network & $79.83 \%$ & 0.65 \\
-500 iterations, 7 hidden nodes & & \\
$\quad$ Neural Network & $79.40 \%$ & 0.63 \\
-700 iterations, 7 hidden nodes & & 0.59 \\
$\quad$ Neural Network & $70.81 \%$ & 0.74 \\
\hline -1000 iterations, 7 hidden nodes & $85.10 \%$ & \\
Support Vector Machine &
\end{tabular}




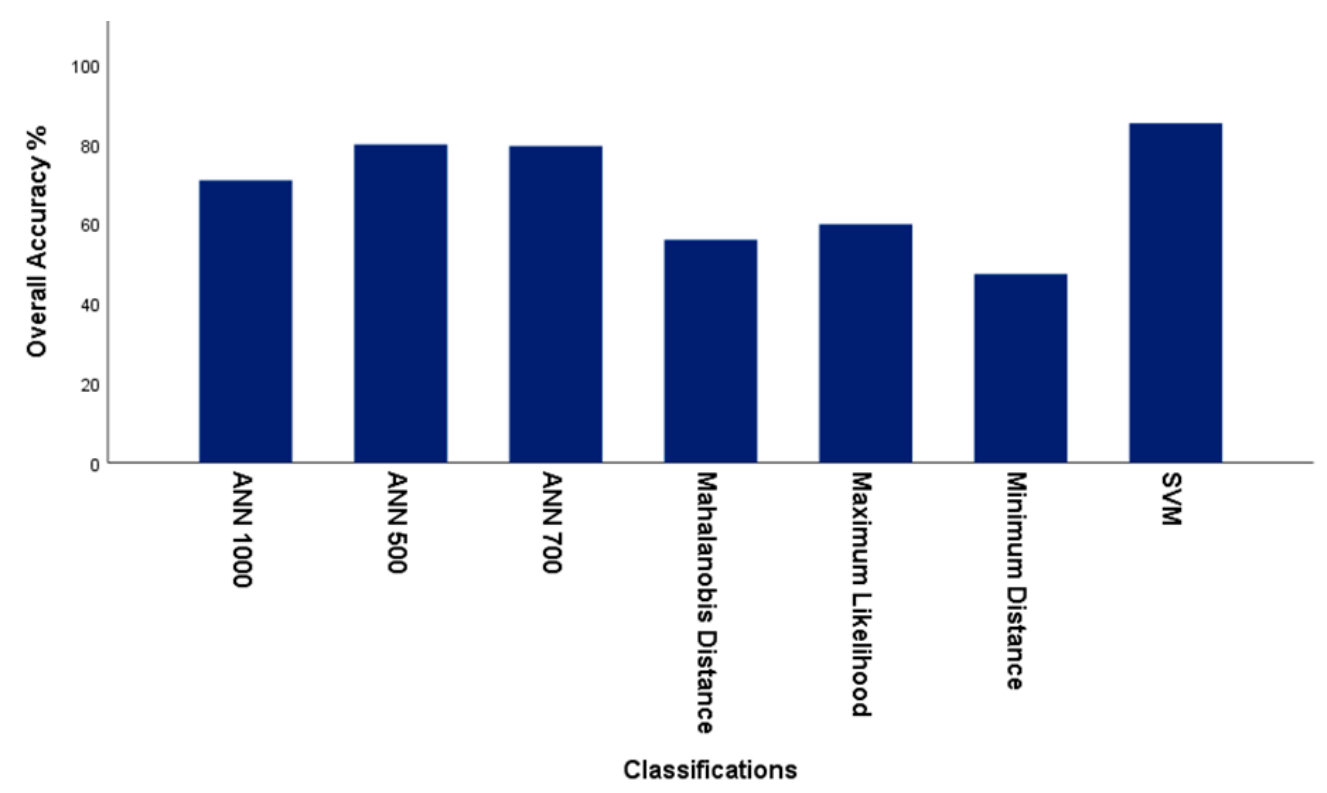

Figure 15. The overall accuracy of five types of classifications using machine learning and conventional-based approach.

\subsubsection{Accuracy Assessment from SVM Classification}

The overall accuracy of the selective logging impacts from the SVM classification was $87.40 \%$. This was validated by comparing the classification results to ground truth data, ensuring comparable values. During the SVM classification process, six classes were chosen as training data. The highest accuracy was found in the forest and roads, followed by skid trail, stump identification, fell log and objects (car). SVM has an overall accuracy of $87.4 \%$ and a Kappa value of 0.8 (Table 7).

Table 7. Support vector machine classification accuracy.

\begin{tabular}{ccccc}
\hline Class & UA & PA & CE & OE \\
\hline Stump & 65.71 & 70.05 & 29.95 & 34.29 \\
Road & 85.11 & 96.30 & 14.89 & 3.70 \\
Skid Trail & 75.70 & 44.56 & 24.30 & 55.44 \\
Fell Log & 56.10 & 86.89 & 43.90 & 13.11 \\
Forest & 99.62 & 99.73 & 0.38 & 0.27 \\
Car & 65.75 & 8.04 & 34.25 & 91.96 \\
Overall Accuracy & \multicolumn{2}{c}{$87.40 \%$} \\
Kappa Coefficient & \multicolumn{2}{c}{0.77} \\
\hline
\end{tabular}

\subsection{Forest Canopy Gaps}

The high-resolution UAV orthomosaic image with canopy gaps of less than $3 \mathrm{~m}$ height was distinguishable in the Ulu Jelai logging region (roads, skid trails, and forest canopy gaps). The CHM height below $3 \mathrm{~m}$ effectively identified the gaps produced by logging operations (Figure 16). In between each compartment, the areas were calculated. The areas of roads showed the highest value in compartment 159 in both methods (1.12 ha and 1.08 respectively) and decreased for compartments 160 and 124 . While for skid trails, compartment 160 had the largest areas in both methods with the areas of 0.99 ha and 0.94 respectively. With respect to the forest canopy gaps, the highest loss values were observed in compartment 159 ( 2.30 ha and 4.52 ha in two methods respectively) followed by compartments 160 and 124 . The total area of noticeable gaps due to logging using automated approaches was calculated to be 8.93 ha out of a total of 48.00 ha covered by UAV flights (Table 8 ). This area represents $18.6 \%$ of the mapped logged area. The manual 
digitization of selected logging damage inroads ( 2.51 ha), skid trails (1.68 ha), and forest gaps and felled logs (6.08 ha) resulted in a total logging effect of 10.27 ha (Figure 17).

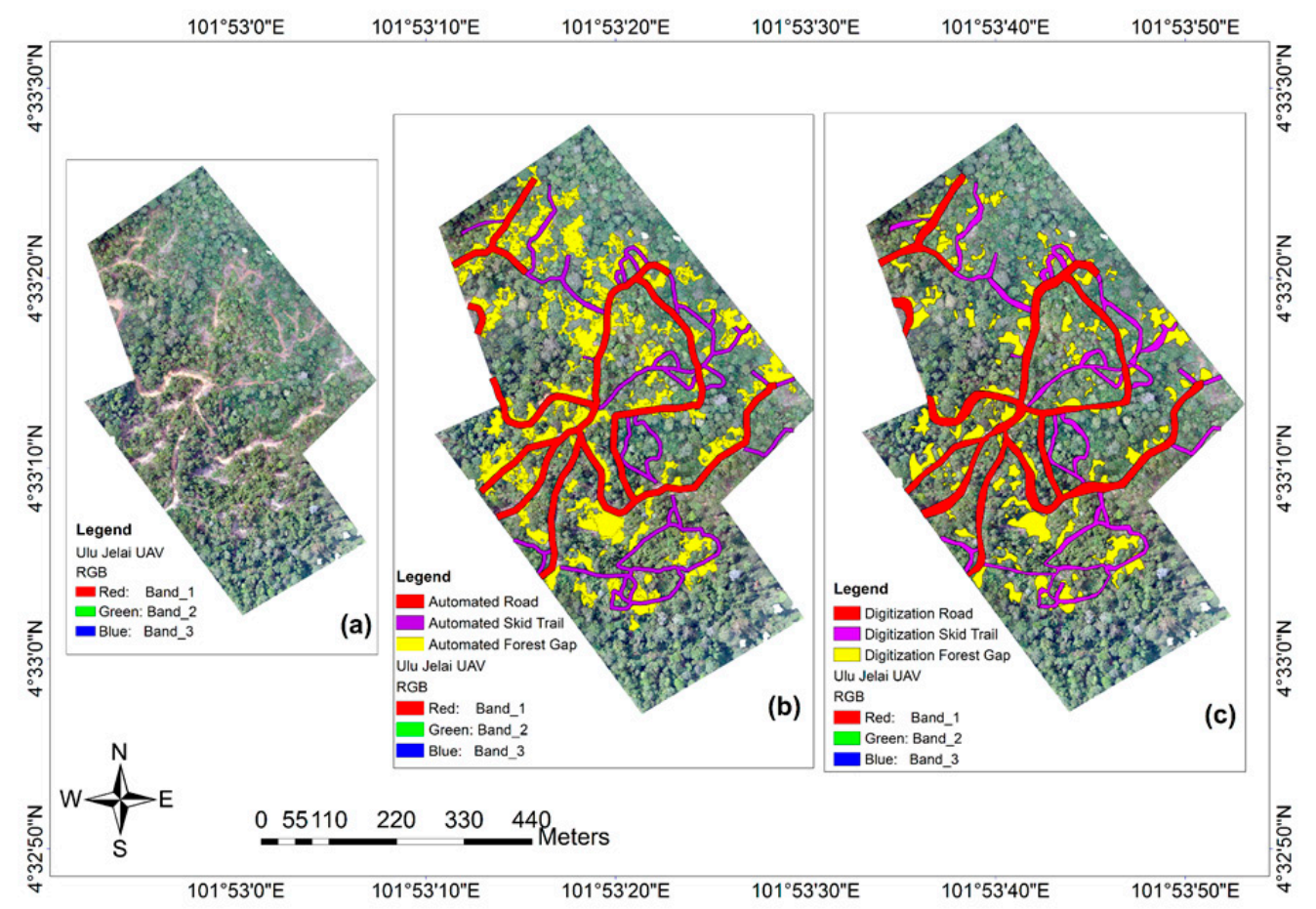

Figure 16. The extracted map of roads, skid trails and forest canopy gaps of (a) UAV image; (b) automatic detection; and (c) manual digitization.

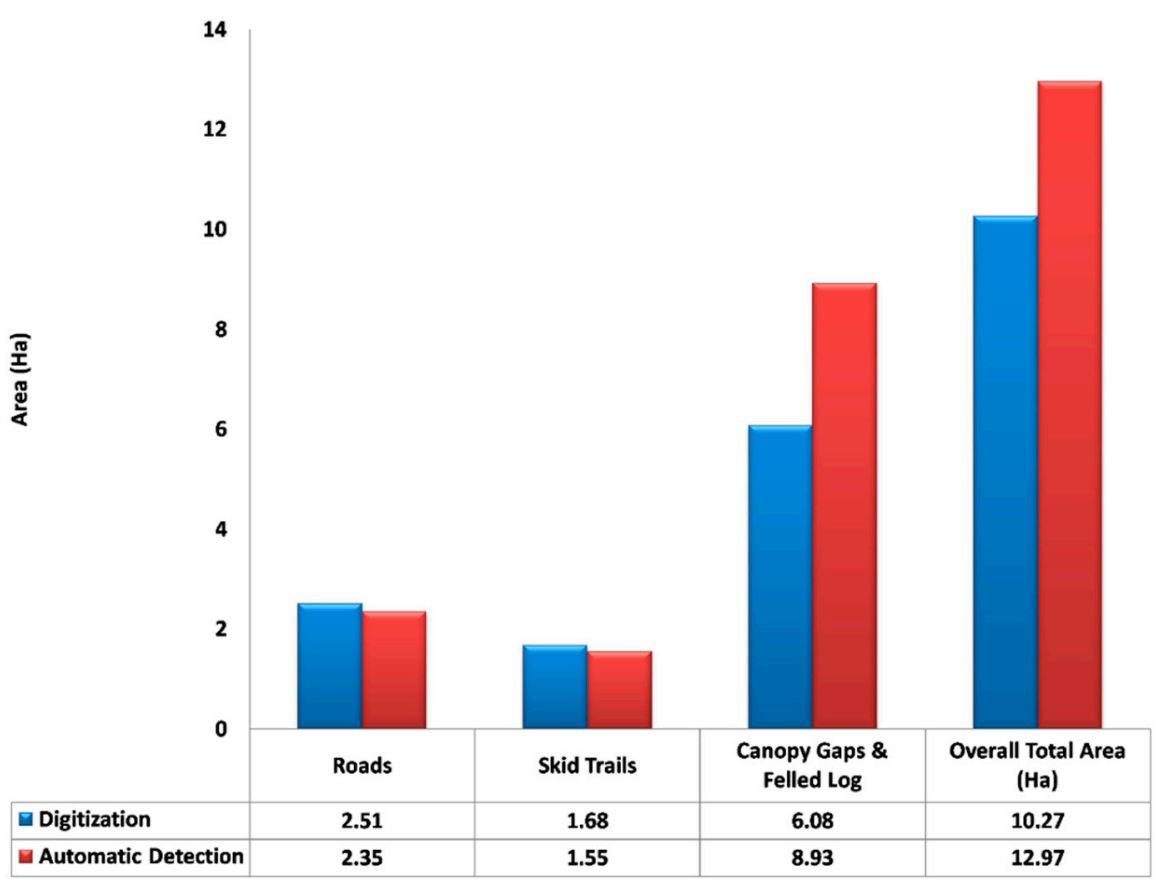

Figure 17. Area comparison between automatic and manual detection methods in detecting roads, skid trails and forest canopy gaps area.

Differences in road, skid trail and forest gaps were caused mainly by automatic detection related to tree crown projections, and this approach overestimated the manual digitization of forest canopy gaps. In this study, automated forest gap areas produced gaps 
that included bigger border regions, standing trees and residual vegetation crowns as part of the impacted area (Figure 18). This is due to the data being captured six months after the logging activities conducted in the Ulu Jelai forest reserve area. The variables in Table 8 highlight the most significant variances between the two approaches.

Table 8. Area of roads, skid trails and forest canopy gaps between the two approaches.

\begin{tabular}{ccccc}
\hline Methods & Roads (Ha) & $\begin{array}{c}\text { Skid Trails } \\
\text { (Ha) }\end{array}$ & $\begin{array}{c}\text { Forest Gaps and } \\
\text { Felled Log (Ha) }\end{array}$ & $\begin{array}{c}\text { Overall Total } \\
\text { Areas (Ha) }\end{array}$ \\
\hline $\begin{array}{c}\text { Digitization } \\
\text { Compartment 124 }\end{array}$ & 0.47 & 0.35 & 1.98 & \\
Compartment 159 & 1.12 & 0.34 & 2.30 & \\
Compartment 160 & 0.92 & 0.99 & 1.80 & \\
Total Areas (Ha) & 2.51 & 1.68 & 6.08 & \\
Automatic & & & & \\
Detection & & & & \\
Compartment 124 & 0.42 & 0.31 & 2.18 & \\
Compartment 159 & 1.08 & 0.30 & 4.53 & \\
Compartment 160 & 0.85 & 0.94 & 2.22 & \\
Total Areas (Ha) & 2.35 & 1.55 & 8.93 & \\
\hline
\end{tabular}

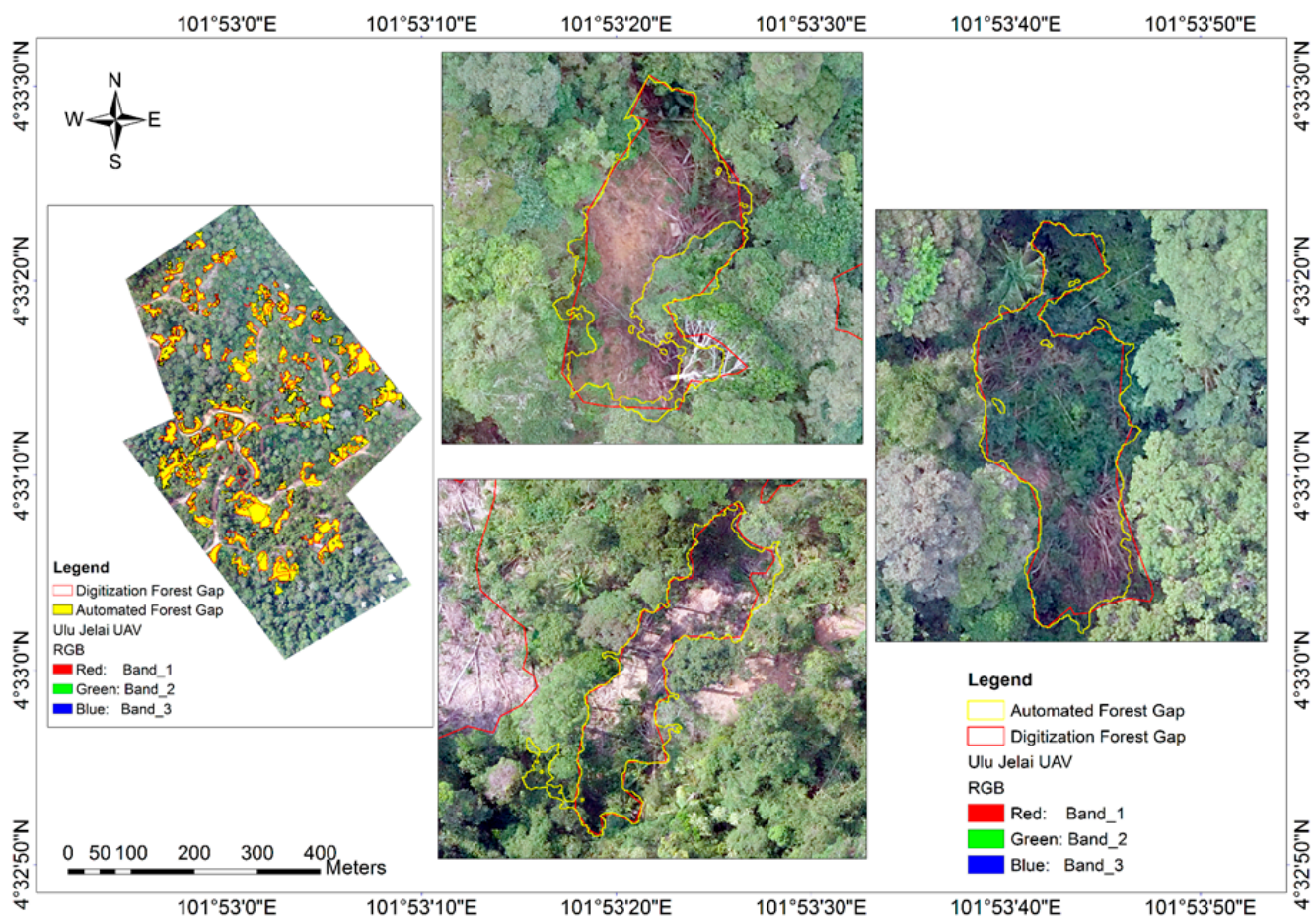

Figure 18. The differences in identifying forest canopy gaps using an automated vs. manual technique.

\section{Discussion}

The results revealed that UAV-based RGB and digital elevation models created from overlapped images of UAVs can be utilised to construct cost-effective selective logging impacts in Ulu Jelai, Pahang, Malaysia. The innovation of accurate automated methods for processing UAV data could be of critical help because they would lower the data processing costs, allowing for data acquisition of extensive areas while providing repeatable and consistent estimates of vital forest attributes. To the best of our knowledge, this is the first method in stump extraction from selectively logged areas in the tropical forest using the integration of TM and OBIA, whereas many studies tend to only apply the OBIA technique alone. These studies discovered that: (i) Integration of TM and OBIA has the 
higher accuracy compared to OBIA only; (ii) SVM classification is a suitable classification for identifying the selective logging impacts; and (iii) the forest canopy gaps area impacted by the logging activities was $18.6 \%$ of the total study area.

\subsection{Detection of the Tree Stumps Using Integration of TM and OBIA}

This study provided two methods for obtaining tree stump information using UAV images in post-selective logging site measurements. This is an application where UAVs may be the only remote sensing data platform capable of obtaining such comprehensive information with acceptable levels of accuracy at particular time in post selective logging areas. Only a few research projects have employed tree-stump detections collected from UAV data till now. The ability to recover information at a low cost, on the other hand, may lead to the creation of applications in which its usage might be advantageous on a larger scale. As a result, this study presented some of these applications, revealing the potential of UAV-derived tree-stump detection strategies. Since this study works with a recently developed research topic, the detection accuracy measurement findings can only be compared to those found in previous research by [13]. When it comes to accurate detection by each technique, segmentation, and object detection, the studies complement each other, and the methods are equivalent to those studied by [14]. The proposed approaches are unlikely to function effectively in instances when large portions of trees are left standing as some tree stumps would be obscured by the canopy.

The suggested detection technique for OBIA had an overall accuracy of $66.9 \%$, and merged TM and OBIA had an overall accuracy of $75.8 \%$, with all harvesting residues remaining on site. After all, in a research by [13], the percentages of omission (20.1-32.1\%) and commission errors (26-34.7\%) were lower than those obtained in this study (14.3-33.3\% and $16.7-50 \%$, respectively). Identifying a variety of non-tree-stump items, such as logging residuals and boulders, produced the omission errors, whereas the commission errors were caused mainly by extreme discolouration or non-visibility of the tree-stump surface. It is also worth keeping in mind that the results in this study were acquired in one mission of a single UAV flight under consistent good weather and light conditions. Image processing and a greater understanding of the best circumstances for various UAV applications might help to mitigate some of these negative impacts.

In the future, there is a need for higher accuracy stump detection data, and for that the most suitable time to fly may be within two months after the logging activities. This research contributes by introducing new levels of analysis obtained from post-harvest UAV images. While the results were positive on one side, it is critical to validate and enhance these findings utilising a range of stands and detection and segmentation algorithms. For instance, it would be beneficial to compare the suggested method's performance against picture pattern recognition techniques such as those studied by [14,30]. The prospect of mapping the existence and dispersion using various comparable data, such as LiDAR, is one of the outcomes from the suggested technique that deserves additional research. The retrieval of such data is very costly but can offer higher accuracy.

\subsection{Performance of the Classifications}

This study examined the performance of machine learning classification that include the SVM and ANN. From the remote sensing perspective and performance study, these machine learning classifications are also being compared with the three conventional classification methods which are maximum likelihood, minimum distance and Mahalanobis distance classifier. The performance of these classifications has the potential of highresolution aerial data from an unmanned aerial vehicle to map the impacts on selective logging on post logging areas in Ulu Jelai, Pahang, Malaysia. The imagery used in the study area also classified the stumps, which is the main indicator for the post logging followed by roads, skid trail and felled log. Previous studies showed that tree species maps obtained from commonly used medium-spatial-resolution [19], but for this study indicates 
that the imagery below $0.10 \mathrm{~m}$ from the UAV is also very suitable for selective logging impacts identification and mapping.

The comparison between SVM and ANN was employed to investigate their ability in forest mapping. Both SVM and ANN algorithms achieved comparable overall accuracies. In between the three ANN classification results with different iterations, it shows that 500 iterations perform the higher accuracy compared to 700 iterations and 1000 iterations, which are set as parameters before running the process. Considering the processing time duration, more iterations being added will result in more time being consumed. The output results map, produced among these three parameters, shows slightly different but comparable overall accuracy. This finding is supported by [31], who also showed that lower iterations are adequate for the high-resolution imagery and this at the same time it saves time of the processing. There were no research studies conducted with the comparison of five classifications yet but in this study SVM produced higher classification accuracy than ANN by about $6 \%$ followed by maximum likelihood when UAV data were used. As we can see from Table 6, SVM created better results than the ANN and other classifiers for its overall accuracy and kappa coefficient. This is supported by the findings by $[19,25,32]$. Nonetheless, the level of SVM accuracy is quite common in the remote sensing image classification studies that looked at mapping vegetation and tree species level as in [23]. The result varies from $70-80 \%$ from these two machine learning classifiers influenced by the capturing data area after six months of the selective logging date. In the context of calculation complexity, it agrees very well with the study by [19]. The overall accuracy percentage produced by SVM is $85.10 \%$ by using RBF kernel parameters. The "one-against-

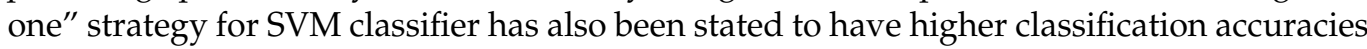
in a study by $[25,32]$.

\subsection{Forest Canopy Gaps by Logging Area}

The findings of canopy cover and forest gap mapping using DSM and DTM obtained from overlapped images were promising for forest gap detection. In addition, gap extraction from a ready CHM was very time effective, which was crucial for application across vast regions. The classification of the open forest was defined as a critical stage in the procedure. This is a crucial characteristic for many forest species, therefore it is a useful by-product of this research. Canopy cover estimation performed well in both completely open areas and areas with a mix of an open and dense forest stands, with the majority of uncertainties occurring in areas with intermediate canopy cover (i.e., close to the predefined threshold of $30 \%$ cover for differentiation between open and dense forest). Where areas of mismatch between automated detection and visual interpretation of gap characteristics were detected, the presence of canopy leaves below the gaps considerably affected the method's performance. Due to the difficulties of ground identification, the existence of vegetation leaves above gaps, and not always orthogonal tree projection in 3D-view UAV's overlapped images, several doubts emerged during visual interpretation in this example. Additionally, when verifying canopy openings located along road axes, gaps on roads were potentially overestimated, influenced by the visual interpreter's perception and automatic complementation of linear features, therefore the manual interpretation and automatic detection divided the roads, skid trails, and forest canopy gaps to avoid the overestimated area. Due to the restrictions of accessing each site one by one from the ground, visual evaluation over field assessments for validation was selected [20]. It is important to have a solid connection between the remote sensing data and the field evaluation. Even if field evaluations are conducted after remote sensing data has been gathered, fast vegetation growth in response to the increasing intensity of the light in canopy openings may have an impact on validation outcomes. It is good to visually and automatically identify the roads, skid trails and forest canopy gaps separately; therefore, will minimize the error in the output results. In this study, the overall gap density in the study region was calculated. In each compartment, the areas were being analysed. In both methods, roads consist of the largest area in compartment 159, skid trails show the highest areas in compartment 
160 and the largest forest loss occurs in compartment 159 . Therefore, $18.6 \%$ of the mapped gap area was identified in the logging area of Ulu Jelai. A study by [6] used a dataset combination of UAV and LiDAR in the automated approach for canopy gap detection. The result obtained was that gaps mapped from the canopy height model were correctly classified when compared to visual assessments at $8 \%$ accuracy from the total mapped area. This is comparable with the results achieved in this study when extrapolating the total size area.

\section{Conclusions}

Selective logging can create several impacts to the forest structure pattern, including the left stump on-site, roads, skid trails, felled logs and forest canopy gaps. This study suggests efficient remote sensing techniques to analyse the impacts of selective logging activity. One of them is integrating various machine learning techniques and conventional classifiers using UAV data to detect the stumps as the primary indicator of selective logging impacts. Forest structure was efficiently mapped by machine learning classifiers where SVM offers the best accuracy with $85 \%$ compared to ANN classifiers. For tree stump detection, integrating template matching and OBIA techniques had achieved higher accuracy than OBIA alone, with an accuracy of more than $75 \%$. Further detection of canopy gaps resulted in good accuracy using an automated method. The effect of logging on the percentage of canopy loss was $18.6 \%$ from the original forest areas. The results indicate that the study site's UAV-based data and elevation information were applicable and reliable with reasonable accuracy for analysing selective logging impacts. This information is significant to the forester and relevant authority to manage logging activity that may be sustained longer. However, more research is always needed to improve the research framework and advanced technology such as modern UAVs in RTK mode and LiDAR for a better analysis.

Author Contributions: All the authors have made a substantial contribution toward the successful completion of this manuscript. Conceptualization, A.M.M.K. and W.S.W.M.J.; methodology, A.M.M.K. and W.S.W.M.J.; software, A.M.M.K. and S.N.M.S.; validation, A.M.M.K., S.N.M.S. and W.S.W.M.J.; formal analysis, A.M.M.K., S.N.M.S. and W.S.W.M.J.; investigation, A.M.M.K., W.S.W.M.J., K.N.A.M., H.O. and S.N.M.S.; resources, A.M.M.K., W.S.W.M.J., K.N.A.M., H.O.; data curation, A.M.M.K.; writing-original draft preparation, A.M.M.K., W.S.W.M.J. and S.N.M.S.; writing-review and editing, A.M.M.K., W.S.W.M.J., K.N.A.M., H.O., S.N.M.S. and M.M.; visualization, A.M.M.K., S.N.M.S and W.S.W.M.J.; supervision, W.S.W.M.J. and K.N.A.M.; project administration, A.M.M.K.; funding acquisition, W.S.W.M.J. All authors have read and agreed to the published version of the manuscript.

Funding: The authors gratefully acknowledge the funding for this research work supported under Geran Universiti Penyelidikan with grant no: GUP-2018-132. The APC was funded by Geran Galakan Penyelidik Muda with grant no: GGPM-2020-034.

Acknowledgments: We would like to thank Forest Research Institute Malaysia (FRIM), Pahang Forestry Department, and the Earth Observation Centre, Institute of Climate Change, Universiti Kebangsaan Malaysia (UKM) for providing fieldwork equipment and access to the secondary data.

Conflicts of Interest: The authors declare no conflict of interest.

\section{References}

1. Saiful, I.; Latiff, A. Effects of Selective Logging on Tree Species Composition, Richness and Diversity in a Hilldipterocarp Forest in Malaysia. J. Trop. For. Sci. 2014, 26, 188-202.

2. Wan Mohd Jaafar, W.S.; Abdul Maulud, K.N.; Muhmad Kamarulzaman, A.M.; Raihan, A.; Md Sah, S.; Ahmad, A.; Saad, S.N.M.; Mohd Azmi, A.T.; Jusoh Syukri, N.K.A.; Razzaq Khan, W. The Influence of Deforestation on Land Surface Temperature-A Case Study of Perak and Kedah, Malaysia. Forests 2020, 11, 670. [CrossRef]

3. Hethcoat, M.G.; Edwards, D.P.; Carreiras, J.M.B.; Bryant, R.G.; França, F.M.; Quegan, S. A Machine Learning Approach to Map Tropical Selective Logging. Remote Sens. Environ. 2019, 221, 569-582. [CrossRef]

4. Jaafar, W.S.W.M.; Said, N.F.S.; Maulud, K.N.A.; Uning, R.; Latif, M.T.; Kamarulzaman, A.M.M.; Mohan, M.; Pradhan, B.; Saad, S.N.M.; Broadbent, E.N.; et al. Carbon Emissions from Oil Palm Induced Forest and Peatland Conversion in Sabah and Sarawak, Malaysia. Forests 2020, 11, 1285. [CrossRef] 
5. Böttcher, H.; Eisbrenner, K.; Fritz, S.; Kindermann, G.; Kraxner, F.; McCallum, I.; Obersteiner, M. An Assessment of Monitoring Requirements and Costs of Reduced Emissions from Deforestation and Degradation. Carbon Balance Manag. 2009, 4, 7. [CrossRef]

6. D’Oliveira, M.V.N.; Figueiredo, E.O.; de Almeida, D.R.A.; Oliveira, L.C.; Silva, C.A.; Nelson, B.W.; da Cunha, R.M.; de Almeida Papa, D.; Stark, S.C.; Valbuena, R. Impacts of Selective Logging on Amazon Forest Canopy Structure and Biomass with a LiDAR and Photogrammetric Survey Sequence. For. Ecol. Manag. 2021, 500, 119648. [CrossRef]

7. Shimabukuro, Y.E.; Beuchle, R.; Grecchi, R.C.; Achard, F. Assessment of Forest Degradation in Brazilian Amazon Due to Selective Logging and Fires Using Time Series of Fraction Images Derived from Landsat ETM+ Images. Remote Sens. Lett. 2014, 5, 773-782. [CrossRef]

8. Achard, F.; Defries, R.; Eva, H.; Hansen, M.; Mayaux, P.; Stibig, H.J. Pan-Tropical Monitoring of Deforestation. Environ. Res. Lett. 2007, 2, 045022. [CrossRef]

9. Ab Rahman, A.A.; Wan Mohd Jaafar, W.S.; Abdul Maulud, K.N.; Noor, N.M.; Mohan, M.; Cardil, A.; Silva, C.A.; Che'YYa, N.N.; Naba, N.I. Applications of Drones in Emerging Economies: A Case Study of Malaysia. In Proceedings of the IEEE 2019 6th International Conference on Space Science and Communication (IconSpace), Johor Bahru, Malaysia, 28-30 July 2019; pp. 35-40.

10. Maizah Saad, S.N.; Abdul Maulud, K.N.; Mohd Jaafar, W.S.W.; Muhmad Kamarulzaman, A.M.; Omar, H. Tree Stump Height Estimation Using Canopy Height Model at Tropical Forest in Ulu Jelai Forest Reserve, Pahang, Malaysia. IOP Conf. Ser. Earth Environ. Sci. 2020, 540, 012015. [CrossRef]

11. He, K.; Zhang, X.; Ren, S.; Sun, J. Deep Residual Learning for Image Recognition. In Proceedings of the IEEE Computer Society Conference on Computer Vision and Pattern Recognition 2016, Las Vegas, NV, USA, 27-30 June 2016; pp. 770-778. [CrossRef]

12. Afrasinei, G.M.; Melis, M.T.; Buttau, C.; Bradd, J.M.; Arras, C.; Ghiglieri, G. Assessment of Remote Sensing-Based Classification Methods for Change Detection of Salt-Affected Areas (Biskra Area, Algeria). J. Appl. Remote Sens. 2017, 11, 016025. [CrossRef]

13. Puliti, S.; Talbot, B.; Astrup, R. Tree-Stump Detection, Segmentation, Classification, and Measurement Using Unmanned Aerial Vehicle (UAV) Imagery. Forests 2018, 9, 102. [CrossRef]

14. Kalantar, B.; Mansor, S.B.; Shafri, H.Z.M.; Halin, A.A. Integration of Template Matching and Object-Based Image Analysis for Semi-Automatic Oil Palm Tree Counting in UAV Images. In Proceedings of the 37th Asian Conference on Remote Sensing, ACRS 2016, Colombo, Sri Lanka, 17-21 October 2016; Volume 3, pp. 2333-2340.

15. Bernales, A.M.J.; Samonte, C.O.; Antolihao, J.A.F.; Silapan, J.R.; Edullantes, B.; Pada, A.V.S.; Dela Serna, A.M.L. Integration of Template Matching and SVM Technique for Coconut Tree Detection. In Proceedings of the 37th Asian Conference on Remote Sensing, ACRS 2016, Colombo, Sri Lanka, 17-21 October 2016; Volume 1, pp. 104-112.

16. Lewis, J.P. Template Matching by Cross Correlation 2 Normalized Cross Correlation. In Proceedings of the Vision Interface 95, Candian Image Processing and Pattern Recognition Society, Quebec City, QC, Canada, 15-19 May 1995; pp. 120-123.

17. Dixon, B.; Candade, N. Multispectral Landuse Classification Using Neural Networks and Support Vector Machines: One or the Other, or Both? Int. J. Remote Sens. 2008, 29, 1185-1206. [CrossRef]

18. Ustuner, M.; Sanli, F.B.; Dixon, B. Application of Support Vector Machines for Landuse Classification Using High-Resolution Rapideye Images: A Sensitivity Analysis. Eur. J. Remote Sens. 2015, 48, 403-422. [CrossRef]

19. Nitze, I.; Schulthess, U.; Asche, H. Comparison of Machine Learning Algorithms Random Forest, Artificial Neuronal Network and Support Vector Machine to Maximum Likelihood for Supervised Crop Type Classification. In Proceedings of the 4th Conference on GEographic Object-Based Image Analysis_GEOBIA 2012, Rio de Janeiro, Brazil, 7-9 May 2012; Volume 79, p. 3540.

20. Zielewska-Büttner, K.; Adler, P.; Ehmann, M.; Braunisch, V. Automated Detection of Forest Gaps in Spruce Dominated Stands Using Canopy Height Models Derived from Stereo Aerial Imagery. Remote Sens. 2016, 8, 175. [CrossRef]

21. Zhou, H.; Zhang, Y.; Yu, Z. Image Classification Based on Region of Interest Detection. In Proceedings of the Pattern Recognition and Computer Vision 2015, Boston, MA, USA, 7-12 June 2015; Volume 9813, p. 98130U. [CrossRef]

22. Kolios, S.; Stylios, C.D. Identification of Land Cover/Land Use Changes in the Greater Area of the Preveza Peninsula in Greece Using Landsat Satellite Data. Appl. Geogr. 2013, 40, 150-160. [CrossRef]

23. Omer, G.; Mutanga, O.; Abdel-Rahman, E.M.; Adam, E. Performance of Support Vector Machines and Artificial Neural Network for Mapping Endangered Tree Species Using WorldView-2 Data in Dukuduku Forest, South Africa. IEEE J. Sel. Top. Appl. Earth Obs. Remote Sens. 2015, 8, 4825-4840. [CrossRef]

24. Seetha, M.; Muralikrishna, I.V.; Deekshatulu, B.L.; Malleswari, B.L.; Hegde, P. Artificial Neural Networks and Other Methods of Image Classification. Theor. Appl. Inf. Technol. 2008, 4, 1039-1053.

25. Al-Ahmadi, F.S.; Hames, A.S. Comparison of Four Classification Methods to Extract Land Use and Land Cover from Raw Satellite Images for Some Remote Arid Areas, Kingdom of Saudi Arabia. J. King Abdulaziz Univ. Earth Sci. 2009, 20, 167-191. [CrossRef]

26. Kalra, K.; Kumar Goswami, A.; Gupta, R. A Comparative Study of Supervised Image Classification Algorithms for Satellite Images. Int. J. Electr. 2013, 1, 10-16.

27. Khan, U.; Minallah, N.; Junaid, A.; Gul, K.; Ahmad, N. Parallelepiped and Mahalanobis Distance Based Classification for Forestry Identification in Pakistan. In Proceedings of the 2015 International Conference on Emerging Technologies, ICET 2015, Peshawar, Pakistan, 19-20 December 2015; IEEE: Piscataway, NJ, USA, 21 January 2016. [CrossRef]

28. See, L.; Laso Bayas, J.; Schepaschenko, D.; Perger, C.; Dresel, C.; Maus, V.; Salk, C.; Weichselbaum, J.; Lesiv, M.; McCallum, I.; et al. LACO-Wiki: A New Online Land Cover Validation Tool Demonstrated Using GlobeLand30 for Kenya. Remote Sens. 2017, 9, 754. [CrossRef] 
29. Asner, G.P.; Mascaro, J. Mapping Tropical Forest Carbon: Calibrating Plot Estimates to a Simple LiDAR Metric. Remote Sens. Environ. 2014, 140, 614-624. [CrossRef]

30. Huo, L.; Lindberg, E. Individual Tree Detection Using Template Matching of Multiple Rasters Derived from Multispectral Airborne Laser Scanning Data. Int. J. Remote Sens. 2020, 41, 9525-9544. [CrossRef]

31. Wijaya, A. Application of Multi-Stage Classification to Detect Illegal Logging with The Use of Multi-Source Data; International Institute for Geo-Information Sience and Earth Observation: Enschede, The Netherlands, 2005; p. 77.

32. Ojaghi, S.; Ebadi, H.; Ahmadi, F.F. Using Artificial Neural Network for Classification of High Resolution Remotely Sensed Images and Assessment of Its Performance Compared with Statistical Methods. Am. J. Eng. Technol. Soc. 2015, 2, 1-8. 